\title{
Simulação numérica do fluído em mancais radiais com superficies texturizadas a laser sob regime de lubrificação hidrodinâmico
}

\section{Davi das Chagas Neves}

Dissertação apresentada à Ârea Interunidades em Ciència e Engenharia de Materiais, da Universidade de São Paulo, para obtenção do título de Mestre em Ciência e Engenharia de Materiais.

Orientador: Prof. Dr. Antonio Carlos Hernandes 


\section{Neves, Davi das Chagas}

"Simulação numérica do fluido em mancais radiais com superficies texturizadas a laser sob regime de lubrificação hidrodinâmico" / Neves, Davi das Chagas - São Carlos, 2006

Dissertação (Mestrado) - Instituto de Física de São Carlos, Escola de Engenharia de São Carlos e Instituto de Quimica de São Carlos da Universidade de São Paulo, 2006 - 72 pag.

Área: Engenharia e Ciência dos Materiais

Orientador: Prof. Dr. Antônio Carlos Hernandes

1. Simulação numérica, mancal radial ,campo de pressão, capacidade de carga, lubrificação hidrodinâmica e texturização a laser

I. Titulo 
Universidade de São Paulo

Ciência e Engenharia de Materiais

Fone (16) 3373.9589 - Fax (16) 3373-9777

MEMBROS DA COMISSÃO JULADORA DA DISSERTAÇÃO DE MESTRADO DE DAVI DAS CHAGAS NEVES, APRESENTADA A ÁREA INTERUNIDADES CIÊNCIA E ENGENHARIA DE MATERIAIS, UNIVERSIDADE DE SÃO PAULO, EM 05/06/2006.

COMISSÃO JULGADORA:

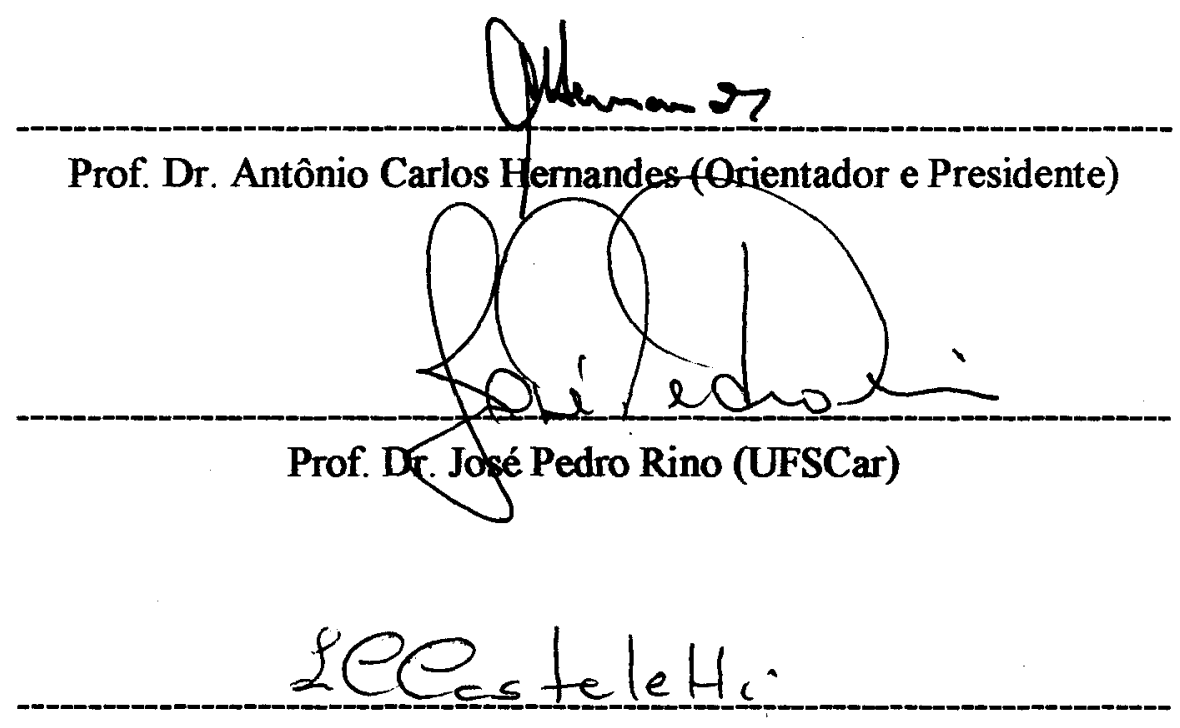

Prof. Dr. Luiz Carlos Casteletti (EESC / USP)

USP - Educação para o Brasil

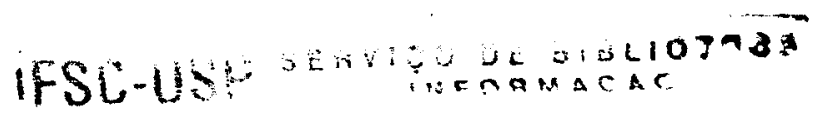


Dedico este trabalho aos meus pais por serem uma lição de dignidade, humildade e honestidade. Não importa o titulo que eu tenha, meu maior orgulho sempre será o de ser seu filho. 


\section{Agradecimentos}

Ao professor Dr. Antonio Carlos Hernandes, meu orientador e amigo, pelo incontestável apoio e essenciais sugestões durante o trabalho.

Aos professores e funcionários do GCCMC pela amizade e profissionalismo, fundamental para a realização deste trabalho. Agradeço especialmente a Geraldo e Manoel, pela grande amizade.

Aos professores, Esmerindo e Waldek, pelo considerável auxilio e pertinentes sugestōes.

Aos alunos do GCCMC pelo companherismo e amizade, o que considero essencial num ambiente de trabalho.

A república rodox, minha nova casa, pela amizade, auxilio e principalmente pelo apoio nas horas mais dificeis.

Aos amigos e amigas virtuais por me fazerem companhia nas frias madrugadas de São Carlos, juntamente com meus companheiros Pérson e Lauro.

Por fim, agradeço a toda minha familia, pela intensa dedicação, amizade e apoio em todos os momentos da minha vida. Em especial aos meus avós, pela educação que recebi nos primeiros anos de minha vida. 


\section{Sumário}

Lista de Figuras

vii

Lista de Tabelas

viii

Resumo

ix

Abstract

$\mathbf{x}$

1 Introdução

2 A equação de Reynolds 6

2.1 Formulação da equação de Reynolds . . . . . . . . . . . . . . 6

2.2 Classificação da equação de Reynolds . . . . . . . . . . . 11

2.3 Solução numérica da equação de Reynolds . . . . . . . . . . . 15

2.3.1 O método de diferenças finitas . . . . . . . . . 15

2.3.2 Resoluçāo de sistemas algébricos lineares . . . . . . . 21

2.3.3 A determinaçāo da capacidade de carga . . . . . . . . 23

2.4 Erros e precisão de uma solução numérica . . . . . . . . . . . 24

3 A lubrificação em um mancal texturizado 28

3.1 Os regimes de lubrificação . . . . . . . . . . . . . . 28

3.2 Análise da lubrificação em um mancal radial . . . . . . . . . . . 32

3.2.1 A espessura mínima do filme lubrificante . . . . . . 32

3.2.2 A auto-pressurização em mancais radiais . . . . . . . 35 
3.3 O efeito da texturização na lubrificação do mancal . . . . . . . 38

3.4 o processo texturização superficial . . . . . . . . . . 40

4 Resultados e discussão $\quad 45$

4.1 Adimensionalização da equação de Reynolds . . . . . . . . . 45

4.2 A precisão e estabilidade do algoritmo . . . . . . . . . 48

4.3 Análise das alterações no campo de pressão . . . . . . . . . . 50

4.4 As características ideais para as cavidades $\ldots \ldots \ldots \ldots$

4.4.1 A forma e as dimensōes da cavidade . . . . . . . . 53

4.4.2 A densidade superficial das cavidades em uma placa . . . 58

5 Conclusões $\quad 64$

6 Anexos $\quad 66$

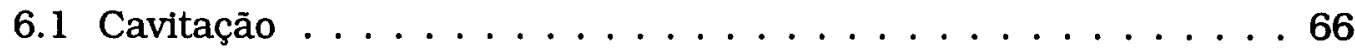

6.2 Elementos de computação . . . . . . . . . . . . . 67

6.2 .1 Os comandos do software Maple . . . . . . . . . . . 67

6.2 .2 O algoritmo utilizado . . . . . . . . . . . 69 


\section{Lista de Figuras}

1.1 Visāo transversal de um mancal radial hidrodinâmico. A espessura do filme está desproporcional. . . . . . . . . . . . 3

2.1 Campo de velocidade do fluido escoando entre duas placas, sendo que a placa superior está sob açāo de uma tensão cisalhante $\tau$. $\quad 7$

2.2 Duas placas separadas por um filme lubrificante com espessura

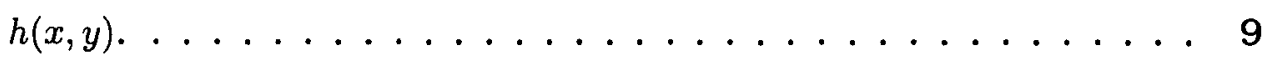

2.3 Regiāo $\Omega$ que representa o dominio da solução de uma EDP qual-

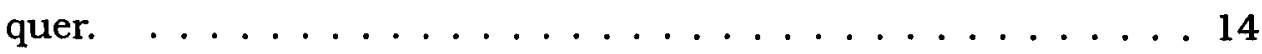

2.4 Representação de uma malha bidimensional, onde $x_{0}=y_{0}=1$ assim como os passos $\Delta x$ e $\Delta y . \ldots \ldots 16$

2.5 Representação da metodologia utilizada pelo MDF para equações elipticas e hiperbólicas. . . . . . . . . . . . . 21

2.6 Representação do método de nove pontos Laplaciano (MDF) utilizado geralmente para equações elípticas. . . . . . . . . . . 26

3.1 Duas superfícies deslizantes, com a rugosidade ressaltada. . . . 29

3.2 Regimes de lubrificação segundo o parâmetro $\lambda[51]$. . . . . . . . 32

3.3 Mancal radial girando no sentido horário, provocando o deslocamento do eixo para a esquerda, na figura. . . . . . . . . . . 34

3.4 Diagrama que apresenta a relação de $N_{S} \operatorname{com} h_{o} \ldots \ldots$. . . . 35 
3.5 O óleo é esguichado através do furo no alojamento devido a pressão criada pela rotação do eixo (sentido anti-horário). . . . . 36

3.6 Campo de pressão em um fluido escoando por um canal convergente e divergente. . . . . . . . . . . . . 37

3.7 Representação em detalhe da região estudada no mancal texturizado, onde, $R_{S}$ é o raio do eixo, que gira com uma velocidade angular $\omega \ldots \ldots \ldots \ldots \ldots \ldots$. . . . . . . . . . . . . . .

3.8 Distribuição de pressão para um eixo parcialmente texturizado (linha azul) e totalmente texturizada (linha vermelha). . . . . . . 40

3.9 Campo de pressão em um mancal radial, devido ao efeito de auto-pressurização. . . . . . . . . . . . . . . 41

3.10 Incidência do feixe de laser no material (alvo). . . . . . . . . 43

4.1 Duas placas deslizantes, sendo que uma esta texturizada. . . . 46

4.2 Determinação da capacidade de carga para uma cavidade cônica, conforme refina-se a malha. Definindo, $\Psi=1, \gamma=2.58$ e $\xi=2,64$, como os parâmetros persentes no algoritmo (Anexo 6.2). . . . . 50

4.3 Solução numérica (576 pontos) para um fluido escoando entre duas placas planas. . . . . . . . . . . . . 51

4.4 Solução numérica (576 pontos) para um fluido escoando entre duas placas com uma cavidade. . . . . . . . . . . . . 52

4.5 Representação tridimensional das quatro formas estudadas. . . . 54

4.6 Comparaçao entre campo de pressão de cavidades semi parabólica

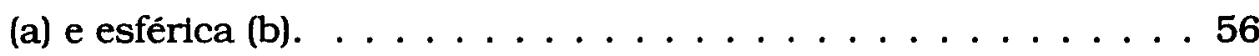

4.7 Variação do fator $\Psi$ que representa a profundidade da cavidade. . 57

4.8 Determinação do Diâmetro Ideal . . . . . . . . . . . . . 58

4.9 Placa texturizada com comprimento L e, ao lado, uma célula imaginária. . . . . . . . . . . . . . . . . 59 


\section{Lista de Tabelas}

3.1 Rugosidade típica para alguns componentes mecânicos [50]. . . . 29

4.1 Relação dos parâmetros utilizados no algoritmo com as características da microcavidade. . . . . . . . . . . . 48

4.2 Valores médios da capacidade de carga, para as quatro formas propostas, com seus respectivos desvios padrões. . . . . . . . 55

4.3 Os parâmetros de texturas para um dado $h_{o}$ ou uma dada rugosidade $R a . \ldots \ldots 63$ 


\section{Resumo}

O desgaste e a vida útil dos componentes mecânicos é uma questão de grande interesse econômico e tecnológico, devido suas diversas aplicações. Estudos tribológicos recentes apresentam novas soluçōes para esta questão, como a texturização superficial a laser, cujo o propósito é aumentar a eficiência do processo de lubrificação nestes componentes. Este trabalho analisa, por meio de um modelo teórico, os efeitos desta textura superficial no processo de lubrificação hidrodinâmico em mancais radiais. Este modelo é elaborado a partir da equação de Reynolds, cuja solução representa o campo de pressão no fluido lubrificante, determinando assim o escoamento deste em mancais radiais. A solução desta equação foi obtida através de um algoritmo desenvolvido no software Maple, utilizando o método de diferenças finitas. A partir deste campo de pressão, determina-se a capacidade de carga do mancal, definida como um parâmetro de qualidade da lubrificação, afinal, quanto maior for a capacidade de carga melhor será o processo lubrificação. Através de simulações computacionais, foram determinadas as dimensões, densidade superficial e forma das microcavidades que maximizam a capacidade de carga, aprimorando desta manetra o processo de lubrificação e estabelecendo um padrão ideal de textura superficial para o mancal. Convém ressaltar que, nestas simulações, a análise de cada uma das características das micro-cavidades foram realizadas variando-se os parâmetros (no algoritmo) relacionados a elas, como foi proposto pelo modelo teórico. 


\section{Abstract}

The wear and the shelfl life of mechanical components are a question of great economic and technological interest, had its diverse applications. Recent tribologics studies show new solutions for this question, as the laser surface texturing, whose the intention is to increase the efficiency of the lubrication process in these components. This work analyzes, means of a theoretical model, the effect of this surface textured in the hydrodynamic process of lubrication in journal bearings. This model is developed from the equation of Reynolds, whose solution represents the pressure distribution in the lubricant fluid, then determining the draining of this in journal bearings. The solution of this equation was gotten by means of an algorithm developed in the Maple software, using the finite difference methods. From this pressure distribution, the load capacity of the journal bearing is determined, defined as a quality parameter of the lubrication, after all, how much bigger will be the load capacity better will be the lubrication process. Means of computational simulations had been determined, the measures, surface density and shape of the microholes that maximize the load capacity, improving in this way the lubrication process and set out an ideal standard of surface texture to the bearing. Is important stand out that, in these simulations, the analysis of each characteristic of the micro-holes was carried through varying parameters (in the algorithm) related to these, as was considered by the theoretical model. 


\section{Capítulo 1}

\section{Introdução}

A durabilidade e o desempenho de um elemento de máquina estāo ligados a eficiência do processo de lubrificação em seus componentes. O atrito entre duas peças de um componente mecânico depende das caracteristicas das superficies atritantes e do lubrificante que as separam [1, 2]. Em vista disso, as modificaçōes superficiais apresentam-se como uma alternativa para melhorar a lubrificação em diversos componentes mecânicos [3, 4, 5].

Estas modificações podem ser classificadas conforme suas dimensões, sendo as micro-modificaçōes $(\mu m)$, em geral, linhas ou cavidades produzidas por texturização superficial $[5,6]$.

O efeito das micro-modificações superficiais no processo de lubrificação foi inicialmente estudado por Hamilton (1966) e Anno (1969). Eles mostraram que a presença de micro-cavidades na superficie de duas placas deslizantes, separadas por um filme lubrificante fluido, produz uma distribuição de pressão assimétrica local, devido o efeito de cavitação ${ }^{1}$; gerando uma capacidade de carga suplementar que auxilia na lubrificação destas placas [5, 7].

Posteriormente, Snegovsky (1983) e Lai (1994) observaram que cavidades e linhas, com pequena profundidade, auxiliam a lubrificação de selos mecânicos aumentando a separação mínima entre suas faces [5, 7].

\footnotetext{
${ }^{1} O$ fenômeno de cavitação está apresentado no anexo 6.1
} 
Em 1996, Etsion e Busrtein desenvolveram um modelo teórico para analisar o processo de lubrificação em selos mecânicos, contendo uma rede superficial de micro-cavidades hemisféricas. Utilizando este modelo, eles demonstraram que as caracteristicas destas micro-cavidades estão vinculadas à eficiência do processo de lubrificação neste componente [7, 8].

A partir destes trabalhos $[5,8]$ outros estudos foram realizados com o propósito de otimizar as características das micro-cavidades para alguns componentes mecânicos: selos, pistões, mancais axiais, etc. Todos estes trabalhos [9-19] foram motivados pelo efeito coletivo destas micro-cavidades na produção de uma capacidade de carga adicional, tornando assim a lubrificação mais eficiente.

Recentemente em [13, 14], analisou-se o desempenho da lubrificação em mancais axiais texturizados com micro-cavidades hemisféricas, sendo designada uma densidade superficial ótima para as micro-cavidades em torno de 13\%, no caso de uma texturização completa. Para a texturização parcial do mancal axial, não foi apresentada uma densidade superficial ótima. Estes resultados foram obtidos analisando-se a capacidade de carga do lubrificante fluido.

Analogamente em [17] Marian e Pascovici desenvolveram um modelo, similar àquele apresentado em [13], para avaliar o desempenho da lubrificação em duas placas deslizantes texturizadas. Neste trabalho [17], as caracteristicas geométricas das micro-cavidades foram avaliadas por meio da pressão máxima que o fluido exerce sobre as placas, correlacionada com a capacidade de carga. Os resultados obtidos mostraram que a profundidade ótima, das micro-cavidades, está em torno de $70 \%$ do valor da espessura mínima do filme lubrificante fluido $\left(h_{0}\right)$.

Convém salientar que, a texturização superficial (produção das microcavidades) pode ser realizada por meio de ablação laser, como foi sugerido 
a principio nos trabalhos [5, 8]. O processo de texturização superficial a laser $\left(\mathrm{LST}^{2}\right.$ ) é rápido e fornece um excelente controle da forma e tamanho das micro-cavidades, sendo introduzldo na comunidade tribológica em 1990 [17], a partir de entāo a aplicaçāo deste método de texturização tem ganhado cada vez mais atenção [20-23]. No entanto, deve-se ressaltar que existe outras técnicas de texturização superficial envolvendo processos fisicos e quimicos, como mostra os trabalhos $[17,24,25]$.

Em outros trabalhos recentes [26-31], têm-se analisado o efeito da rugosidade superficial na distribuição de pressão (capacidade de carga) de diversos componentes mecânicos, tal como o mancal radial. Este componente mecânico é constituido por um eixo envolto num fluido lubrificante, ambos contidos dentro de um alojamento (fig. 1.1).

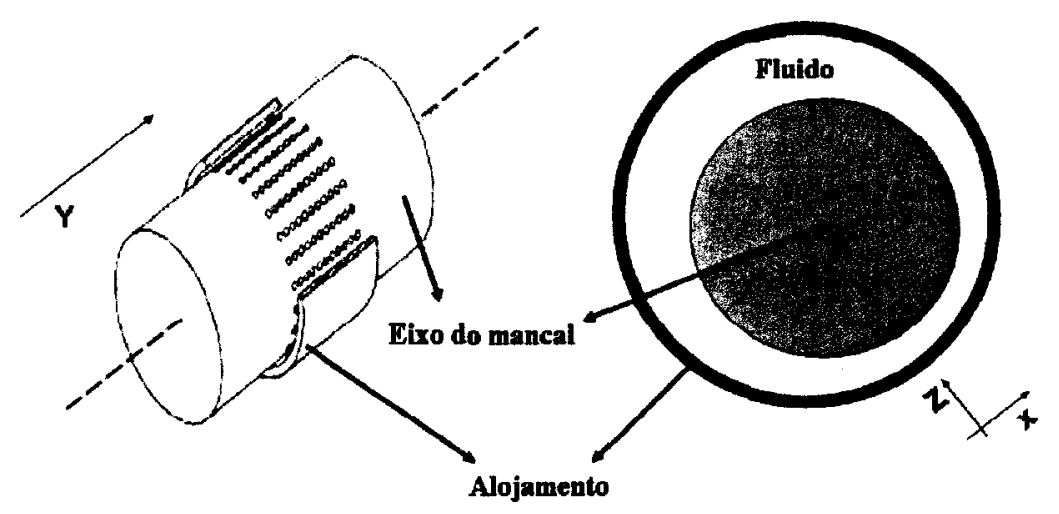

Figura 1.1: Visão transversal de um mancal radial hidrodinâmico. A espessura do filme está desproporcional.

\footnotetext{
${ }^{2}$ Laser Surface Texturing
} 
O mancal radial está presente em vários equipamentos mecânicos, tais como: compressores, bombas, turbinas, motores, etc; em vista disso, o aprimoramento da lubrificação neste componente é algo de grande interesse industrial. Motivados por este argumento, muitos trabalhos [32-39] buscam a otimização da geometria deste componente, avaliando suas características superficiais (rugosidade) e seus parâmetros operacionais .

No presente trabalho, analisa-se um mancal radial sob o regime de lubrificação hidrodinâmico, logo o efeito da rugosidade sobre a distribuição de pressão pode ser desconsiderado, caso o mancal esteja texturizado. Logo, deve-se avaliar o efeito das micro-cavidades no processo de lubrificação deste componente, por meio da capacidade de carga, conforme foi sugerido em trabalhos anteriores $[5,7,17]$.

Utilizando o software Maple, em conjunto com o método de diferenças finitas, determina-se a solução da equação de Reynolds e conseqüentemente a capacidade de carga do mancal radial (Anexo 6.2). A partir da capacidade de carga, serão analisadas quatro formas diferentes para as micro-cavidades, com volumes similares, sendo que algumas se mostraram mais eficientes para o processo de lubrificação, maximizando a capacidade de carga; dai, a partir de uma forma mais eficiente, determina-se as outras caracteristicas para as micro-cavidades.

O presente trabalho foi dividido da seguinte maneira:

No segundo capítulo apresenta-se a equação de Reynolds, determinando sua fórmula e classificação. A seguir, define-se o método numéricos utilizados para obter a solução numérica desta equação, relacionada com a capacidade de carga ${ }^{3}$. Por fim, descreve-se os possiveis erros cometidos pelo algoritmo computacional, na determinação da solução numérica.

O terceiro capitulo, define os regimes de lubrificação, geralmente encontra-

\footnotetext{
${ }^{3}$ Parâmetro utilizado para avaliar a eficiência da lubrificaçāo
} 
dos nos componentes mecânicos, determinando assim o regime que se encontra o mancal. Em seguida apresenta-se os parâmetros operacionais utilizados para o projeto de um mancal; definine-se então o efeito de texturização na lubrificação, por meio da capacidade de carga. Finalmente, descreve-se como se realiza a texturização com laser, analisando o processo de ablação.

Logo após, no quarto capítulo, apresenta-se uma versão adimensionalizada para a equação de Reynolds, que será utilizada nos cálculos. Os resultados obtidos a partir desta equação, com o algoritmo desenvolvido neste trabalho (Anexo 6.2), são apresentados e discutidos. Enfim, analisa-se estes resultados e faz-se uma discussão comparando e determinando as caracteristicas ideais das cavidades produzidas na texturização.

Enfim, complementando o trabalho, apresenta-se a conclusão conforme os resultados obtidos e, em seguida, apresenta-se nos anexos uma definição do efeito de cavitação e o algoritmo utilizado na realização das simulações. 


\section{Capítulo 2}

\section{A equação de Reynolds}

A distribuição de pressão no fluido lubrificante é essencial para a compreensão do processo de lubrificação hidrodinâmica em componentes mecânicos. Esta distribuição é definida pela solução da equação de Reynolds, a qual será formulada e classificada neste capítulo. Ainda, neste capitulo, serão apresentados os métodos numéricos utilizados para a determinação desta solução. Por fim, analisa-se os possiveis erros cometidos durante a determinação da solução numérica.

\subsection{Formulação da equação de Reynolds}

A equação de Reynolds representa o escoamento de um fluido, logo ela deve ser determinada utilizando a equação de Navier-Stokes em conjunto com a equação de continuidade. Antes de desenvolver esta equação, deve-se fazer algumas considerações sobre o fluido modelado.

O fluido utilizado neste modelo deve ser definido como Newtoniano e incompressível, pois sua viscosidade e densidade permanecem constantes durante o escoamento, apresentando desta maneira uma proporcionalidade entre a tensão de cisalhamento e o gradiente de velocidade ${ }^{1}$ (fig. 2.1). O escoamento

\footnotetext{
${ }^{1}$ Em um fluido Newtoniano pode-se definir que $\tau=\frac{\partial u}{\partial y}$, sendo $u$ a componente da velocidade
} 
será considerado como laminar, isto é, não haverá turbulência em qualquer ponto do fluido $[40,41]$.

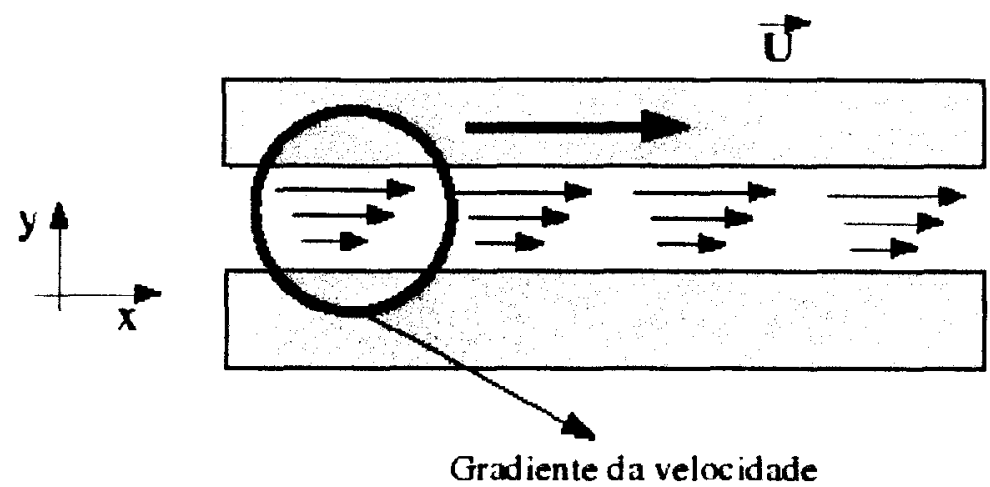

Figura 2.1: Campo de velocidade do fluido escoando entre duas placas, sendo que a placa superior está sob ação de uma tensão cisalhante $\tau$.

Para a dedução da equação de Reynolds, iniciemos apresentando a equação de continuidade que representa o princípio de conservação da matéria, sendo definida como;

$$
\frac{\partial \rho}{\partial t}+\operatorname{div}(\rho \vec{U})=0
$$

onde $\rho$ é a densidade do fluido, $\vec{U}(x, y, z, t)^{2}$ representa seu campo de velocidade e o termo $\rho \vec{U}=\vec{J}$ é, normalmente, definido como densidade do fluxo de massa, ou densidade de corrente.

Também apresentamos a equação de Navier-Stokes;

$$
(\vec{U} \cdot \vec{\nabla}) \cdot \vec{U}+\frac{\partial \vec{U}}{\partial t}=-\frac{1}{\rho} \vec{\nabla} \cdot p+\frac{\mu}{\rho} \cdot \nabla^{2} \cdot \vec{U}
$$

$\overrightarrow{\vec{U}}$, como ilustra a figura 2.1 .

${ }^{2}$ Vale ressaltar que o vetor velocidade pode ser decomposto em três componentes: $\vec{U}=$ $u . \hat{x}+v \cdot \hat{y}+w . \hat{z}$. 
onde $p$ é a pressão e $\mu$ a viscosidade. Esta equação pode ser determinada a partir da lei de conservação do momento, como está demonstrado em [40].

A equação de Navier-Stokes representa, de um modo geral, o escoamento dos fluidos. Entretanto, esta equação geralmente é simplificada devido a sua complexidade. Em 1886, Osborne Reynolds, simplificando a equação de Navier-Stokes, desenvolveu a equação que leva seu nome. Esta equação é utilizada para determinar o campo de pressão no fluido lubrificante em mancais radiais. $[2,42]$.

Entretanto, antes de deduzir a equação de Reynolds é pertinente fazer as seguintes considerações:

1. Considere um fluido ${ }^{3}$ entre duas placas, sendo que a placa superior move-se com velocidade linear $\vec{U}$, enquanto a outra placa permanece estática (fig. 2.2). Adiante (Cap. 3) será demonstrado que este modelo é válido para um mancal radial.

2. As forças de volume, lado esquerdo da equação (2.2), assim como os termos de inércia, são desprezadas quando comparadas com a força de viscosidade, portanto:

$$
\frac{d \vec{U}}{d t}=0
$$

3. A espessura $h$ do fluido lubrificante é muito menor que suas outras dimensões, afinal, trata-se de um filme (fig. 2.2).

4. A condição de superfície é assumida, ou seja, na fronteira superficial a velocidade do fluido coincide com a velocidade da superfície [42].

Aplicando as considerações anteriores a equação (2.2), encontramos que;

$$
\frac{1}{\rho} \vec{\nabla} \cdot p=\frac{\mu}{\rho} \cdot \nabla^{2} \cdot \vec{U}
$$

\footnotetext{
${ }^{3}$ As caracteristicas deste fluido foram descritas na seção anterior.
} 

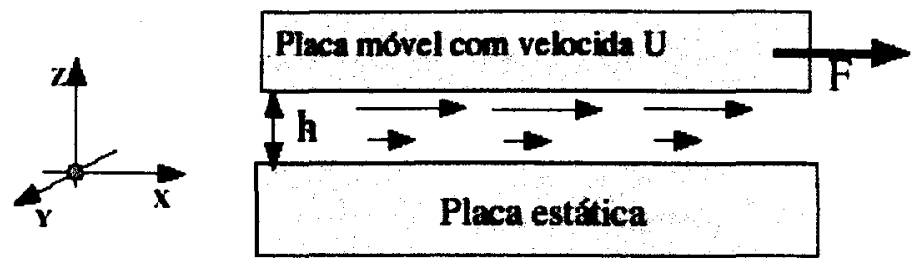

Figura 2.2: Duas placas separadas por um filme lubrificante com espessura $h(x, y)$.

logo, utilizando a definição do vetor velocidade $(\vec{U}=u \hat{x}+v \hat{y}+w \hat{z})$, pode-se expandir esta equação no seguinte sistema de equações:

$$
\begin{aligned}
& \frac{\partial p}{\partial x}=\mu\left(\frac{\partial^{2} u}{\partial x^{2}}+\frac{\partial^{2} u}{\partial y^{2}}+\frac{\partial^{2} u}{\partial z^{2}}\right) \\
& \frac{\partial p}{\partial y}=\mu\left(\frac{\partial^{2} v}{\partial x^{2}}+\frac{\partial^{2} v}{\partial y^{2}}+\frac{\partial^{2} v}{\partial z^{2}}\right) \\
& \frac{\partial p}{\partial z}=\mu\left(\frac{\partial^{2} w}{\partial x^{2}}+\frac{\partial^{2} w}{\partial y^{2}}+\frac{\partial^{2} w}{\partial z^{2}}\right)
\end{aligned}
$$

Supondo que a espessura $h$ do filme esteja na direção $\overrightarrow{O z}$ do sistema (fig. 2.2), pode-se definir que, a componente da velocidade nesta direção deve ser nula ( $w=0)$, conseqüentemente a pressão será considerada constante, ou seja;

$$
\frac{\partial p}{\partial z}=0
$$

eliminando assim a última equaçāo do sistema apresentado anteriormente.

De acordo com a classificação laminar do escoamento e utilizando a primeira e quarta considerações anteriores, pode-se afirmar que todos os gradientes são despreziveis excetuando $\frac{\partial u}{\partial z} \mathrm{e} \frac{\partial v}{\partial z}$, devido a espessura do filme estar na direçāo $\overrightarrow{O z}$. Portanto, o sistema de equaçōes se resume no seguinte:

$$
\begin{aligned}
& \frac{\partial p}{\partial x}=\mu\left(\frac{\partial^{2} u}{\partial z^{2}}\right) \\
& \frac{\partial p}{\partial y}=\mu\left(\frac{\partial^{2} v}{\partial z^{2}}\right)
\end{aligned}
$$

Integrando duas vezes as equações (2.3) e (2.4), são obtidas as seguintes relações: 


$$
u=\frac{1}{2 \mu} \cdot \frac{\partial p}{\partial x} \cdot z^{2}+B \cdot z+C
$$

e

$$
v=\frac{1}{2 \mu} \cdot \frac{\partial p}{\partial y} \cdot z^{2}+D \cdot z+E
$$

Utilizando novamente a primeira e a quarta condição, pode-se determinar as condições de contorno;

$$
\begin{gathered}
u(h)=U \\
u(0)=v(0)=v(h)=0
\end{gathered}
$$

então, substituindo estes valores nas equaçōes anteriores, pode-se definir que:

$$
u=\frac{1}{2 \mu} \frac{\partial p}{\partial x}\left(z^{2}-z h\right)+\frac{U z}{h}
$$

e

$$
v=\frac{1}{2 \mu} \frac{\partial p}{\partial y}\left(z^{2}-z h\right)
$$

Enfim, utilizando a equação de continuidade;

$$
\frac{\partial \rho}{\partial t}+\frac{\partial}{\partial x}(\rho u)+\frac{\partial}{\partial y}(\rho v)+\frac{\partial}{\partial z}(\rho w)=0
$$

e considerando os valores introduzidos anteriormente: $w=0 \mathrm{e} \frac{\partial \rho}{\partial t}=0$. Podemos reescrever esta equaçāo como;

$$
\frac{\partial}{\partial x}(\rho u)+\frac{\partial}{\partial y}(\rho v)=0
$$

dai, utilizando os valores de $u$ e $v$, definidos pelas equações (2.5) e (2.6), e integrando esta equação ao longo da espessura do filme (eixo $\overrightarrow{O z}$ ), considerando as condiçōes de contorno, obtem-se a equação diferencial de Reynolds [2, 42]; 


$$
\frac{\rho}{2 \mu}\left[\frac{\partial}{\partial x}\left(\frac{h^{3}}{6} \frac{\partial p}{\partial x}\right)+\frac{\partial}{\partial y}\left(\frac{h^{3}}{6} \frac{\partial p}{\partial y}\right)\right]+\frac{\partial}{\partial x}\left(\frac{\rho U}{2} h\right)=0
$$

que, reorganizando os termos, será representada pela seguinte expressão:

$$
\frac{\partial}{\partial x}\left(h^{3} \frac{\partial p}{\partial x}\right)+\frac{\partial}{\partial y}\left(h^{3} \frac{\partial p}{\partial y}\right)=6 \mu U \frac{\partial h}{\partial x}
$$

A equação (2.7) é uma versão bastante usual da equação de Reynolds e, embora ela represente um caso especifico, o modelo analisado neste trabalho pode ser representado por sua versão adimensional, como será definido no quarto capítulo.

Através da solução desta equação pode-se determinar, a partir do campo de pressão, diversos parâmetros ligados a eficiência da lubrificação em um mancal radial, como a capacidade de carga, definida pela integral deste campo pela área [42];

$$
W=\iint p(x, y) \cdot d x \cdot d y
$$

porém, vale salientar que, a solução da equação de Reynolds e a capacidade de carga serão determinadas numericamente, conforme será apresentado posteriormente.

\subsection{Classificação da equação de Reynolds}

A equação de Reynolds é uma equação diferencial parcial (EDP), portanto torna-se pertinente a sua classificação, bem como de suas condições de contorno. Geralmente, uma EDP é classificada conforme o número de variáveis independentes contidas em sua expressão, ou ainda, mais especificamente, segundo sua dimesionalidade, definida pelo número de variáveis espaciais. Os problemas de engenharia e de ciências são normalmente tridimensionais, no entanto, eles são elaborados com dimensionalidade menor [43, 44]. 
A ordem de uma EDP será determinada pela derivada parcial de maior ordem que ocorre na equação. Além disso, uma EDP será denominada linear se os termos envolvendo a variável dependente, ou se alguma de suas derivadas parciais, forem de primeiro grau, em caso contrário, a equação pode ser denominada nāo linear ou semi-linear quando ao menos a parte principal ${ }^{4}$ for linear $[43,45]$.

Analisando a equação de Reynolds (2.7), pode-se classificá-la como uma equação bidimensional, com duas variáveis, linear e de segunda ordem, conforme os critérios apresentados. Podemos afirmar ainda, que esta equação pertence a classe de equações elípticas, conforme sugere a teoria de curvas características, apresentada a seguir.

\section{Introdução a teoria das curvas carcterísticas.}

Considerando a EDP satisfazendo as condições descritas anteriormente;

$$
A \cdot \frac{\partial^{2} u}{\partial x^{2}}+2 B \cdot \frac{\partial^{2} u}{\partial x \partial y}+C \cdot \frac{\partial^{2} u}{\partial y^{2}}=\Phi(x, y, u, c t e s)
$$

então, fazendo as seguintes abreviaçōes: $p=\frac{\partial u}{\partial x}, q=\frac{\partial u}{\partial y}, r=\frac{\partial^{2} u}{\partial x^{2}}, s=\frac{\partial^{2} u}{\partial x \partial y} \mathrm{e}$ $t=\frac{\partial^{2} u}{\partial y^{2}}$, define-se as seguintes relaçōes: $d p=r . d x+s . d y$ e $d q=s . d x+t . d y$.

Utilizando a equação e as relações anteriores, pode-se obter o seguinte sistema de equações lineares:

$$
\left[\begin{array}{ccc}
A & 2 B & C \\
d x & d y & 0 \\
0 & d x & d y
\end{array}\right] \cdot\left[\begin{array}{l}
r \\
s \\
t
\end{array}\right]=\left[\begin{array}{c}
\Phi \\
d p \\
d q
\end{array}\right]
$$

A partir de teoremas da álgebra linear, sabe-se que uma condição necessária para que este sistema apresente uma solução (e consequentemente a EDP), é que ele seja linearmente independente. Em outras palavras, o determinante da matriz deve ser diferente de zero para que se verifique esta condição, ou

\footnotetext{
${ }^{4} \mathrm{~A}$ parteprincipal de uma EDP é definida pelos termos de maior ordem [43].
} 
seja:

$$
A . d y^{2}-2 B . d x d y+C . d x^{2} \neq 0
$$

Além disso, este determinante definirá uma equação de segundo grau denominada como a equação caracteristica da EDP:

$$
A . d y^{2}-2 B . d x d y+C . d x^{2}=0
$$

Esta equação pode ser analisada como uma equação de segundo grau, portanto sua solução fornece uma ou duas familias de curvas caracteristicas, proveniente de sua(s) raiz(es):

1. Se $\Delta=A C-B^{2}>0$ ( 2 raizes complexas) a equação denomina-se eliptica.

2. Se $\Delta=A C-B^{2}<0$ (2 raizes reais) a equação denomina-se hiperbólica.

3. Se $\Delta=A C-B^{2}=0$ (1 raiz real) a equação denomina-se parabólica [45].

Analisando a equação de Reynolds (2.7), define-se que $A$ e $C$ são positivos e $B=0$ sempre, logo, pode-se afirmar que esta equação é elíptica, como indica o delta de sua equação caracteristica.

Uma caracteristica importante das equaçōes elípticas é que toda região $\Omega$, domínio da EDP, é imediatamente afetado por qualquer alteração no valor das variáveis dependentes em um ponto qualquer desta região. Deve-se salientar ainda que, a amplitude desta alteração diminui com o aumento da distância ao ponto de pertubação.

Deste modo, pode-se afirmar que, nos problemas estacionários, geralmente representados por equações elípticas, as pertubações variam suavemente dentro do sistema estudado. Esta característica se tornará evidente posteriormente, quando a solução da equação de Reynolds for analisada no quarto capítulo, notando-se uma suave variação no campo de pressão do fluido, devido a alterações no contorno do sistema. 
Por fim, convém ressaltar que, em geral, problemas transientes que apresentam mecanismos de dissipação, são representados, mais adequadamente, por equações parabólicas. As equações hiperbólicas são responsáveis pela modelagem de problemas de vibraçāo ou de convecção, onde fenômenos dissipativos podem ser desprezados $[45,46]$.

\section{Condições de contorno do problema estudado.}

A solução de uma EDP sempre deve se adequar ao modelo que representa, devido a isto, recomenda-se adicionar condições auxiliares para caracterizar melhor o sistema modelado. Estas condições, em geral, serāo denominadas como condiçōes de contorno, por serem definidas sobre o contorno $\Gamma$ do domínio (região) $\Omega$ da equação. Quando a região $\Omega$ for definida sobre a variável temporal, parte das condições de contorno serão denominadas como condiçōes iniciais.

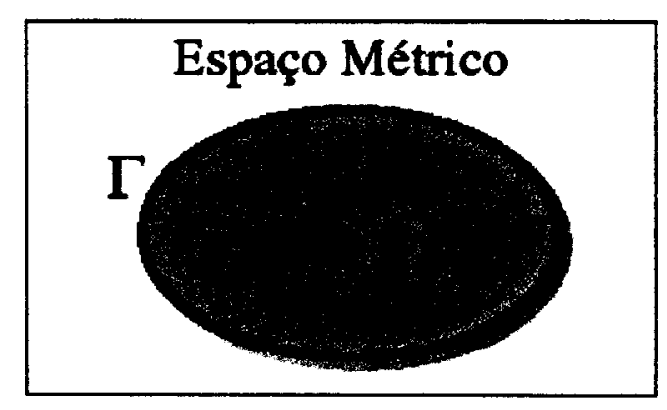

Figura 2.3: Região $\Omega$ que representa o dominio da solução de uma EDP qualquer.

As condições de contorno utilizadas no modelo estudado neste trabalho, são definidas pelo valor da pressão no contorno da região em estudo, este tipo de condiçāo é denominada como de Dirichlet. Quando os valores da solução $u(x, y)$ são conhecidos no contorno $\Gamma$ da região $\Omega$ em estudo, a condição de 
contorno define-se como:

$$
\text { Condição de Dirichlet } \rightarrow\{u(\Gamma)=\text { Cte }
$$

Quando se usa este tipo de condição de contorno, a solução numérica é determinada por um processo denominado direto, pois os valores numéricos são obtidos, a partir dos valores na fronteira, de uma maneira direta.

A determinação das condições de contorno deve ser realizada de maneira cautelosa, porque, caso estas condições sejam prescritas em excesso, haverá imcompatibilidade entre elas e o problema não terá solução e, caso sejam insuficientes, o problema será indefinido apresentando infinitas soluções ${ }^{5}$ $[45,46]$.

\subsection{Solução numérica da equação de Reynolds}

Em geral, a solução da equação de Reynolds deve ser determinada utilizandose métodos numéricos, devido a complexidade da solução analítica. Neste trabalho utiliza-se o método de diferenças finitas, descrito a seguir. Este método, essecialmente, produz um sistemas de equações algébricas a partir de uma equação diferencial. A solução deste sistema de equações é obtida por meio de métodos numéricos como o de Gauss-Seidel, apresentado nesta seção. Por fim, utilizando a solução numérica da equação de Reynolds determina-se a capacidade de carga.

\subsubsection{O método de diferenças finitas}

\section{O fundamento dos métodos numéricos}

A solução numérica de uma $\operatorname{EDP}$ em uma região $\Omega$, implica na obtenção de

\footnotetext{
${ }^{5}$ Tudo isto corrobora com o teorema da unicidade.
} 
valores discretos para a variável dependente. Logo, a discretização da região de domínio $\Omega$ deve ser o primeiro passo a ser realizado. Para EDPs de duas varláveis o processo de discretização da região $\Omega$ produzirá um conjunto de pontos discretos, definidos como a malha desta região.

Em uma malha qualquer, deve-se definir um ponto na origem como $\left(x_{0}, y_{0}\right)$ e então, a partir deste ponto, qualquer outro ponto $(i, j)$ será determinado por $\left(x_{0}+i . \Delta x, y_{0}+j . \Delta y\right)$, sendo $\Delta x$ e $\Delta y$ denominados como o intervalo (ou passo) de discretização sob os eixos da malha. Observando a malha ilustrada na figura 2.4, pode-se deduzir que seu passo é igual a um e que os índices $i$ e $j$ variam de 1 até $N_{i}$ e $N_{j}$ respectivamente.

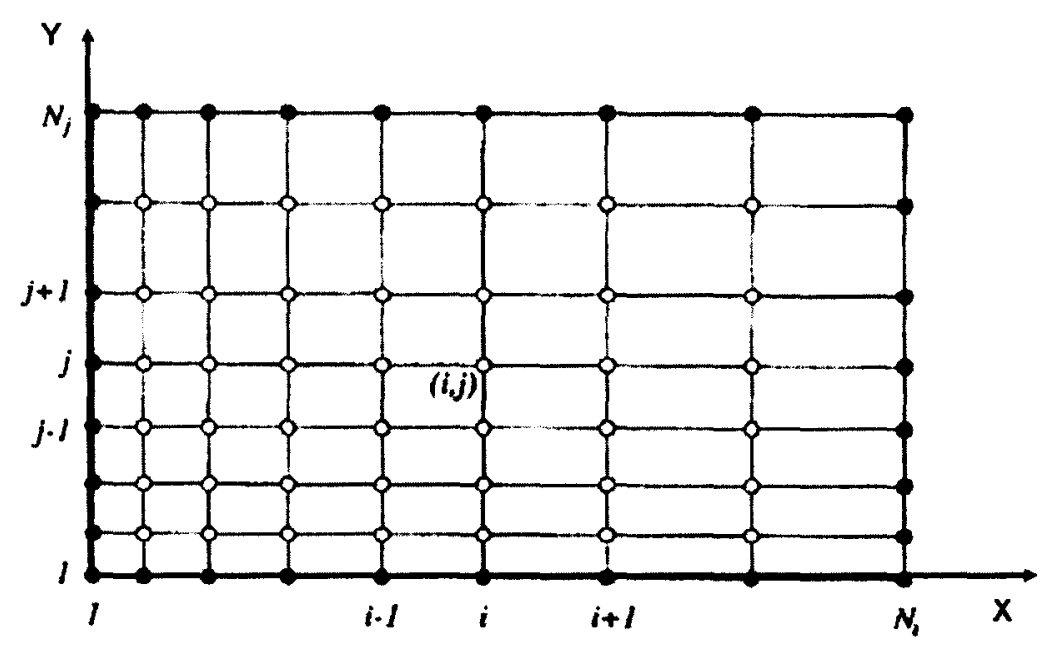

Figura 2.4: Representação de uma malha bidimensional, onde $x_{0}=y_{0}=1$ assim como os passos $\Delta x$ e $\Delta y$.

A solução de uma EDP, em geral, será obtida a partir de valores já determinados em uma sub-região $\Gamma$, ou seja, em outras palavras, a partir dos pontos: $(i, j) \subset \Gamma$, serão calculados seus pontos vizinhos $(i \pm 1, j \pm 1)$, por 
meio de cálculos sucessivos, definindo os valores dos vizinhos adjacentes, até que se cubra toda a região $\Omega$ em estudo, obtendo-se desta forma uma solução aproximada para a EDP.

Há diversos métodos numéricos que usam esta metodologia para encontrar a solução de uma EDP, como o método de diferenças finitas, utilizado neste trabalho, que emprega os termos da série de Taylor para realizar este procedimento. Este método produz, a partir da expressão da EDP, um sistema algébrico de equações numéricas que ao ser solucionado fornece a solução desta equação (EDP) [47].

\section{A formulação do método de diferenças finitas}

A resolução de uma EDP utilizando o método de diferenças finitas (MDF) consiste, essencialmente, na substituição das derivadas parciais contidas na equação diferencial por expressões numéricas, que são na verdade aproximações definidas por uma expansão da série de Taylor truncada.

Este procedimento produzirá, a partir da expressão da EDP, uma equação algébrica para cada ponto da malha, definida como equação de diferenças finita ( $\mathrm{EDF})$, conduzindo a um sistema de equaçōes que relaciona os pontos da malha com seus vizinhos mais próximos, então, resolvendo este sistema obtem-se a solução para a EDP [46].

A determinação da EDF a partir de uma EDP está relacionada a série de Taylor da variável dependente. Então, considerando a expansão da série de Taylor no ponto $x_{i+1}$, definida pela expressão;

$$
u\left(x_{i+1}\right)=u\left(x_{i}\right)+\left.(\Delta x) \frac{\partial u(x)}{\partial x}\right|_{x_{i}}+\left.\frac{(\Delta x)^{2}}{2 !} \frac{\partial^{2} u(x)}{\partial x^{2}}\right|_{x_{i}}+\left.\frac{(\triangle x)^{3}}{3 !} \frac{\partial^{3} u(x)}{\partial x^{3}}\right|_{x_{i}}+\ldots
$$

pode-se determinar que;

$$
\left.\frac{\partial u(x)}{\partial x}\right|_{x_{i}}=\frac{u\left(x_{i+1}\right)-u\left(x_{i}\right)}{\triangle x}+O(\Delta x)
$$


ou de forma abreviada;

$$
\frac{\partial u}{\partial x}=\frac{u_{i+1}-u_{i}}{\triangle x}+O(\Delta x)
$$

Esta expressāo representa uma aproximação de primeira ordem ${ }^{6}$ para primeira derivada de $u(x)$, utilizando diferenças progressivas. A diferença é denominada progressiva porque calculou-se a derivada no ponto $i$ utilizando um ponto adjacente $(i+1)$ da malha.

Sabe-se ainda que, $O(\Delta x)$ são os termos desconsiderados pelo truncamento, denominado como o "resto" da sérle de Taylor e, como será apresentado posteriormente, estes termos estão ligados aos erros de discretização da solução numérica, erros que diminuem a medida que se refina a malha.

Utilizando a série de Taylor no ponto antecedente $(i-1)$ determina-se a diferença denominada atrasada, representada pela expressão:

$$
\frac{\partial u}{\partial x}=\frac{u_{i}-u_{i-1}}{\Delta x}+O(\triangle x)
$$

Deseja-se determinar uma aproximação de segunda ordem, que pode ser definida combinando-se as expansões utilizadas anteriomente, obtendo assim a seguinte expressão para a primeira derivada:

$$
\frac{\partial u}{\partial x}=\frac{u_{i+1}-u_{i-1}}{2 \triangle x}+O(\Delta x)^{2}
$$

A expressão acima é denominada como aproximação de segunda ordem para primeira derivada, com diferenças centrais. Utilizando esta expressão, pode-se reduzir com maior eficiência o erro de truncamento, refinando-se a malha. Contudo, é importante ressaltar que em alguns casos não pode-se utilizar esta expressão, devido as condições de contorno. Porém, utiliza-se a equação (2.11) na elaboração do algoritmo desenvolvido neste trabalho, para resolver EDPs [46, 48].

Combinando novamente as expansões;

\footnotetext{
${ }^{6}$ Porque o termo de menor ordem em $O(\triangle x)$ é de primeira grau.
} 


$$
\begin{aligned}
u\left(x_{i+1}\right) & =u\left(x_{i}\right)+\left.(\triangle x) \frac{\partial u(x)}{\partial x}\right|_{x_{i}}+\left.\frac{(\triangle x)^{2}}{2 !} \frac{\partial^{2} f u(x)}{\partial x^{2}}\right|_{x_{i}}+\left.\frac{(\Delta x)^{3}}{3 !} \frac{\partial^{3} f u(x)}{\partial x^{3}}\right|_{x_{i}}+\ldots \\
& + \\
u\left(x_{i-1}\right) & =u\left(x_{i}\right)-\left.(\triangle x) \frac{\partial u(x)}{\partial x}\right|_{x_{i}}+\left.\frac{(\triangle x)^{2}}{2 !} \frac{\partial^{2} u(x)}{\partial x^{2}}\right|_{x_{i}}-\left.\frac{(\Delta x)^{3}}{3 !} \frac{\partial^{3} u(x)}{\partial x^{3}}\right|_{x_{i}}+\ldots
\end{aligned}
$$

define-se que:

$$
\frac{\partial^{2} u}{\partial x^{2}}=\frac{u_{i+1}-2 u_{i}+u_{i-1}}{(\triangle x)^{2}}+O(\triangle x)^{2}
$$

A equação (2.12) representa a aproximação da segunda derivada, obtida pela expansão truncada da série de Taylor. Esta equação é de segunda ordem, pois, o primeiro termo que aparece no resto da série de Taylor será $\triangle x^{2}$, indicando a ordem da aproximação.

Utilizando as aproximações representadas pelas equações (2.11) e (2.12), pode-se determinar as EDFs para os tipos de EDPs mais usuais ${ }^{7}$. Nesta seção, apresenta-se apenas a formulação para equações elipticas, devido a classificação da equação de Reynolds $[46,47]$.

\section{Obtendo a EDF para equações elipticas}

A obtenção da equação de diferenças finitas para as equações elípticas será realizada utilizando-se as equações $(2.11)$ e (2.12), como será apresentado a seguir. Então, partindo da equação de Reynolds;

$$
\frac{\partial}{\partial x}\left(h^{3} \frac{\partial p}{\partial x}\right)+\frac{\partial}{\partial y}\left(h^{3} \frac{\partial p}{\partial y}\right)=6 \mu U \frac{\partial h}{\partial x}
$$

considerando a seguintes simplificações;

$$
\left\{\begin{array}{c}
h^{3}=c t e=\alpha \\
6 . \mu . U \cdot \frac{\partial h}{\partial x}=0 \\
\frac{\partial h^{3}}{\partial x}=\frac{\partial h^{3}}{\partial y}=0
\end{array}\right.
$$

\footnotetext{
${ }^{7}$ Equações elipticas, parabólicas e hiperbólicas.
} 
pode-se obter a equação de diferenças finitas, substituindo de forma explícita as aproximações (centrais) definidas anteriormente na equação de Reynolds ${ }^{8}$ simplificada;

$$
\alpha .\left(\frac{\partial^{2} p}{\partial x^{2}}+\frac{\partial^{2} p}{\partial y^{2}}\right)=0
$$

e,

$$
\alpha .\left(\frac{p_{i+1, j}+p_{i, j+1}-4 p_{i, j}+p_{i-1, j}+p_{i, j-1}}{k^{2}}\right)=0
$$

sendo que, os intervalos entre os pontos nos eixos da malha são definidos, igualmente, por $k(\Delta x=\Delta y=k)$. Reorganizando os termos pode-se determinar a seguinte fórmula de recorrência:

$$
p_{i, j}=\frac{p_{i+1, j}+p_{i, j+1}+p_{i-1, j}+u p_{i, j-1}}{4}
$$

Analisando a fórmula de recorrência, nota-se que é preciso conhecer o valor de quatro pontos vizinhos pra que se possa determinar o valor da pressão $\left(P_{i, j}\right)$ num ponto $(i, j)$ qualquer. Assim, este método é denominado o método por aproximação de cinco pontos Laplaciano [48].

A vantagem na utilização do Método de Diferenças Finitas, em relação a outros métodos numéricos, é que ele é comparativamente econômico para a montagem do sistema de equações algébricas, devido à simplicidade das operaçōes envolvidas. Por este motivo, este método é freqüentemente utilizado, principalmente para aplicações em áreas como a mecânica dos fluidos, a qual requer a aplicação de uma malha altamente refinada.

A principal dificuldade do MDF consiste em sua aplicação para problemas contendo formas geométricas intrincadas, neste caso o método apresenta dificuldades para o estabelecimento adequado de uma malha. Então, para estes casos, propõe-se utillzar o método de elementos finitos [48, 49].

\footnotetext{
${ }^{8}$ A equação de Reynolds foi transformada na equação de Laplace.
} 


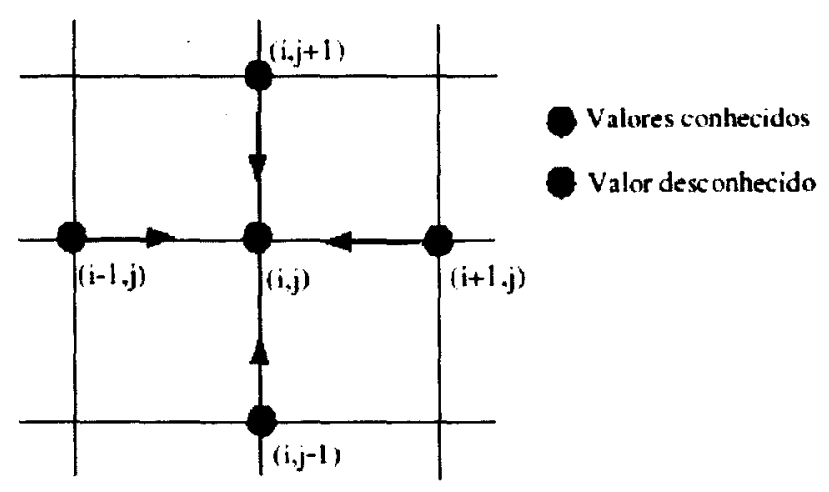

Figura 2.5: Representação da metodologia utilizada pelo MDF para equações elípticas e hiperbólicas.

\subsubsection{Resolução de sistemas algébricos lineares}

Como foi apresentado, o método de diferenças finitas se resume, essencialmente, em transformar uma EDP num sistema de equações algébricas, relacionando os pontos de uma malha. A resolução de um sistema de equaçōes pode ser realizada utilizando-se métodos numéricos tradicionais, que podem ser divididos em dois tipos: diretos e iterativos.

Apresentaremos, a seguir, o método de eliminação de Gauss, como modelo do método direto de obtenção da solução. Em seguida, o método de relaxação de Gauss, como modelo do método iterativo, sendo a solução obtida por meio de iterações.

Vale ressaltar que no algoritmo desenvolvido neste trabalho, apresentado no anexo 6.2, utiliza-se, principalmente, o método de eliminação de Gauss na resolução destes sistemas de equações algébricas lineares.

\section{O método de eliminação de Gauss}

Este método resume-se em duas etapas correlacionadas, sendo que a 
primeira consiste na triangularização (superior) da matriz que representa o sistema linear e a segunda consiste na obtenção da solução a partir de uma fórmula recursiva.

O procedimento de triangularização da matriz é realizado baseando-se na seguinte hipótese da álgebra linear:

"A solução de um sistema linear nāo se altera ao subtrair de uma equação qualquer outra equação do sistema multiplicada por uma constante"

Contudo, pode-se realizar operaçōes entre as linhas de um sistema de equações sem alterar sua solução. Usando estas operações triangulariza-se o sistema.

Enfim, a partir de um sistema triangularizado, pode-se determinar a soluçāo $\left(\vec{X}=\left\{x_{i}\right\}\right)$ do sistema utilizando a fórmula de recorrência definida pela seguinte expressão $[2,49]$;

$$
x_{i}=\frac{1}{a_{i i}}\left[b_{i}-\sum_{j=i+1}^{n} a_{i, j} . x_{j}\right]
$$

determinada para um sistema com ordem $n$.

\section{O método de relaxação de Gauss-Seidel}

O método de relaxação de Gauss-Seldel resume-se em uma única etapa: os valores aproximados da solução de um sistema são determinados por meio de cálculos iterativos assumindo-se um valor inicial para as variáveis desconhecidas. Então, a partir destes valores calcula-se novos valores para estas mesmas variáveis. Este processo continua até que se obtenha uma certa precisão para a solução.

Seja um sistema linear determinável de orden $n$ representado por;

$$
\overleftrightarrow{A} \times \vec{X}=\vec{B}
$$


cuja a solução $\vec{X}$ pode ser obtida por um método iterativo, denominado como método de relaxaçāo de Gauss-Seidel.

Neste método, a solução é determinada utilizando-se a seguinte relação de recorrência:

$$
x_{i}^{(k)}=\frac{1}{a_{i i}}\left[b_{i}-\sum_{j=1}^{i-1} a_{i, j} \cdot x_{j}^{(k)}-\sum_{j=i+1}^{n} a_{i, j} \cdot x_{j}^{(k-1)}\right]
$$

cuja a componente $x_{i}^{(k)}$ do vetor $\vec{X}$ é determinada pela $k$-ésima iteração. Na relação acima, $a_{i, j}$ são os elementos da matriz $\overleftrightarrow{A}$ do sistema de equações e $b_{i}$ são as componentes do vetor $\vec{B}$. O indice $k$ indica o número de iterações. Os indices $i$ e $j$ variam de 1 até $n$, como indica a ordem do sistema.

Devido a erros computacionais, deve-se estabelecer um critério de parada para as iterações. $O$ valor máximo para $k$ está relacionado com a precisão $\delta$ desejada por meio da seguinte expressão:

$$
\frac{\left|x_{i}^{(k)}-x_{i}^{(k-1)}\right|}{\left|x_{i}^{(k)}\right|+\epsilon}<\delta
$$

sendo $\epsilon$ um número muito pequeno $(\epsilon \ll \delta)$ utilizado para evitar a divisão por zero $[2,49]$.

\subsubsection{A determinação da capacidade de carga}

Utilizando os métodos descritos nesta seção, pode-se determinar a solução numérica da equação de Reynolds. Esta solução representa os valores numéricos do campo de pressão $\left(P_{i, j}\right)$ e, a partir destes valores, calcula-se a capacidade de carga utilizando a seguinte expressão;

$$
W=\sum_{i=0}^{N} \sum_{j=0}^{N} P_{i, j} . \Delta x . \Delta y
$$

proveniente da equação $(2.8)$, de modo que as integrais foram substituidas pelos somatórios.

Este parâmetro é essencial na determinação da eficiência do processo de lubrificação, logo, ele será utilizado para avaliar o efeito das texturas sobre a lubrificação. 


\subsection{Erros e precisão de uma solução numérica}

A formulação e a resolução de EDPs por meio do MDF acarreta vários tipos de erros, que estão em geral, associados à abreviações feitas durante a formulação do problema e do próprio método. Nem sempre esses erros são fáceis de identificar, em geral se misturam, podendo ou não haver algum cancelamento.

No entanto, é importante que se conheça estes erros, para que eles sejam levados em consideração no momento de se avaliar a precisão da solução numérica. Portanto, serão apresentados a seguir, alguns tipos de erros freqüentemente encontrados quando se usa o MDF e os erros vinculados a utilização do computador para a realização dos cáculos $[46,49]$.

Erros de discretização $(E D)$

Ao se construir a malha sobre o dominio $\Omega$ da solução, defini-se a magnitude do intervalo $\Delta x$ entre dois pontos, discretizando-se assim esta região. A discretização afeta a solução numérica diretamente. A solução exata é obtida considerando a regiāo $\Omega$ como continua.

A aproximação destas duas soluções, exata e numérica, pode ser realizada tornando o intervalo $\Delta x$ muito pequeno, em outras palavras fazendo $\Delta x \rightarrow 0$. É importante ressaltar que o número de pontos $N$ está inversamente relacionado com o tamanho do intervalo, no caso bidimensional têm-se a relação:

$$
N=\frac{A_{T}}{\Delta x^{2}}
$$

sendo $A_{T}$ a area total da regiāo $\Omega$. Caso $\Delta x \rightarrow 0$, então $N \rightarrow \infty$ e isto é computacionalmente inconcebivel, ainda mais que no MDF cada ponto acarreta uma equação, isto produziria um sistema de ordem infinita.

Assim, o refinamento da malha $(\Delta x \rightarrow 0)$ é uma maneira de aumentar a precisão da solução (redução do erro de discretização), este método está limitado pelos erros computacionais que se propagam durante os cálculos 
aritméticos, como será apresentado a seguir [49].

\section{Erros computacionais $(E C)$ e de arredondamento $(E A)$}

A representação computacional dos números apresentam imprecisões devido a limitações das máquinas durante o arredondamento, acarretando numa flutuação dos valores destes números. Estes erros de arredondamento se propagarão durante os cálculos computacionais (somando-se), produzindo o erro computacional. Este erro limita a capacidade dos computadores em resolver sistemas de equações gigantes. Quanto mais operações forem realizadas, mais arredondamentos serão realizados e mais erros irão se propagar.

Em geral, o tamanho da malha $(N)$, ou a ordem do sistema de equações, deve ser alterado (aumentando) de forma a reduzir o erro de discretização, no entanto, deve-se sempre observar e evitar a relevância dos erros computacionais gerados pelos arredondamentos. Neste trabalho a solução fol analisada para diversos valores de $N$, e foi escolhida uma faixa cujo valor da solução convergia para um valor médio, que foi assumido como o valor exato.

Convém ressaltar que os erros devido a representação computacional dos números, não são os únicos erros de arredondamento. Durante a elaboração do MDF realiza-se um truncamento da série de Taylor que produz outro erro de arredondamento, como será apresentado a seguir.

\section{Erro de truncamento $(E T)$}

Este erro ocorre devido ao truncamento das séries de Taylor utilizadas na elaboração das aproximações numéricas das derivadas parciais para o MDF. Ao truncar a série de Taylor, o termo desconsiderado produz um erro de arredondamento que deverá se propagar (somar) durante os cálculos, denominado como erro de truncamento.

Há duas maneiras de reduzir este erro. Conforme aumenta-se a malha, o valor do termo desprezado pelo truncamento é reduzido, este termo (resto) está diretamente relacionado ao tamanho do intervalo, como foi apresentado 
anteriormente. Em vista disso, o tamanho da malha está limitado pelo erro computacional.

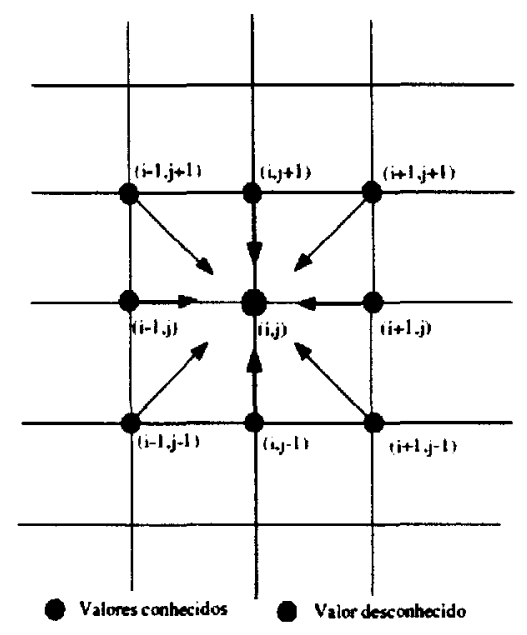

Figura 2.6: Representação do método de nove pontos Laplaciano (MDF) utilizado geralmente para equações elipticas.

A outra maneira de se melhorar a precisão da solução, reduzindo o erro de truncamento, seria aumentando sua ordem, produzindo assim uma diferença finita de alta ordem. Geralmente, isto é realizado utilizando-se o método de nove pontos Laplaciano (fig. 2.6), como foi demonstrado por Smith em [47].

\section{Erros de modelamento (EM)}

Normalmente, durante a elaboração do modelo matemático que representa um fenômeno físico, são feitas algumas simplificações, como por exemplo, supor que coeficientes são constantes e que termos podem ser desprezados. $O$ resultado é que a solução numérica fornecida pela implementação do modelo, em geral apresenta diferenças em relação a solução real do problema físico. Dependendo da magnitude dessas diferenças, a solução obtida pode não ser uma boa representação do fenômeno físico.

Erro geral (EG): 
Uma análise geral dos erros acima pode ser realizada com o propósito de evitar uma solução sem préstimo, portanto deve-se sempre tentar encontar a formalização mais eficiente do problema. Avaliando o erro geral pode-se obter a solução mais precisa, que minimiza este erro. O erro geral pode ser definido como a soma dos erros citados anteriormente, como apresenta a expressão a seguir:

$$
E G=E D+E A+E M
$$

Deve-se ressaltar que a medida que $E D$ é reduzido aumenta-se $E A[46$, 49]. 


\section{Capítulo 3}

\section{A lubrificação em um mancal texturizado}

O processo de lubrificação em um mancal radial depende tanto de seus parâmetros operacionais como do regime de lubrificação em que se encontra. Nesta seção, apresentaremos os regimes de lubrificação e faremos uma análise do processo de lubrificação em um mancal a partir de sua capacidade de carga, logo, este parâmetro será utilizado para analisar o efeito da texturização na lubrificação de um mancal. Por fim, apresenta-se o processo físico envolvido na texturização (produção de micro-cavidades).

\subsection{Os regimes de lubrificação}

O regime de lubrificação em componentes mecânicos é determinado pela topografia das superficies atritantes e pela espessura $h$ do filme fluido que as separam (fig. 3.1).

A topografia de uma superficie, em geral, será definida pela sua rugosidade média $\left(R_{a}\right)$, cujo valor é determinado pela média absoluta dos picos e vales (3.1). Portanto, para uma superficie com $N$ picos e vales, onde a altura (ou profundidade) do k-ésimo pico (ou vale) é dada por $y_{k}[2]$, têm-se que a 


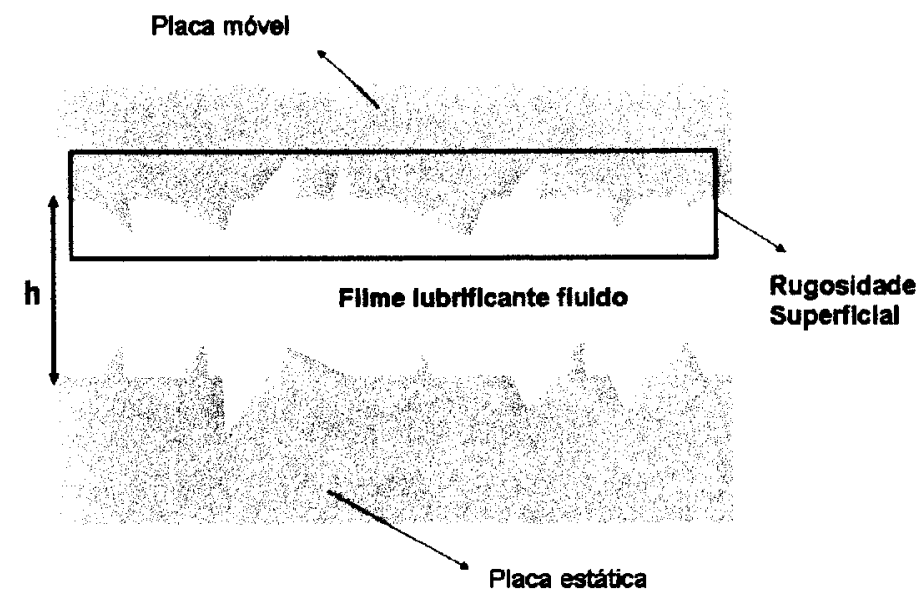

Figura 3.1: Duas superficies deslizantes, com a rugosidade ressaltada.

rugosidade média é representada por:

$$
R_{a}=\frac{1}{N} \sum_{k=1}^{N}\left|y_{k}\right|
$$

A tabela (3.1) apresenta alguns valores de $R_{a}$ para quatro componentes mecânicos.

Tabela 3.1: Rugosidade típica para alguns componentes mecânicos [50].

\begin{tabular}{|c|c|}
\hline Componente mecânico & $R_{a}(\mu \mathrm{m})$ \\
\hline \hline Mancal radial & $0,12-0,80$ \\
\hline Mancal Axial & $0,12-0,25$ \\
\hline Engrenagens & $0,10-0,25$ \\
\hline Mancais de Rolamento & $0,015-0,12$ \\
\hline
\end{tabular}

Os regimes de lubrificação podem ser designados pelo parâmetro $\lambda$, definido como a razão entre a espessura $h$ do filme lubrificante e a rugosidade média 
$R_{a}$ da superficie:

$$
\lambda=\frac{h}{R_{a}}
$$

A seguir apresenta-se as caracteristicas da interação de duas superficies atritantes, conforme seu regime de lubrificação.

\section{Regime de lubrificação limite}

No regime de lubrificação limite, as superficies atritantes estão separadas apenas pelos filmes lubrificantes adsorvidos ${ }^{1}$, acarrentando num possivel contato entre seus picos e vales. Então, neste regime, pode-se definir que;

$$
\lambda \leq 1
$$

ou seja, a rugosidade superficial $R_{a}$ é maior ou igual a espessura $h$ do filme lubrificante. Neste caso, ocorre um atrito seco entre estas superficies e, conseqüentemente, o coeficiente de atrito torna-se elevado $[2,51]$.

\section{Regime de lubrificação misto}

Neste regime, haverá regiōes onde as superficies atritantes estão muito próximas, ocorrendo eventualmente algumas interaçōes entre seus picos e vales, devido ao deslocamento local do fluido que acarreta em casuais rompimentos do filme lubrificante. Entretanto, como este fato é ocasional, não se pode classificar o atrito como seco, e além disso, a lubrificação não é eficiente o bastante para ser definida como hidrodinâmica. Neste caso, o regime de lubrificação é definido como misto e o parâmetro $\lambda$ será:

$$
1<\lambda<3
$$

Analisando as propriedades fisicas do lubrificante, pode-se afirmar que a ocorrência de um rompimento do filme lubrificante, devido a diminuição da

\footnotetext{
${ }^{1}$ Adsorção é a fixação de moléculas de gases ou liquidos na superficie de outra substância. normalmente um sólido.
} 
sua espessura, está associada a efeitos mecânicos e térmicos, acarretando num aumento acentuado do atrito $[2,52]$.

Convém salientar que, este regime de lubrificação apresenta coeficientes de atrito muito baixo para alguns valores de $\lambda$, entretanto seu dominio é restrito, como ilustra a figura 3.2 .

\section{Regime de lubrificação hidrodinâmico}

No regime de lubrificação hidrodinâmico a espessura do filme lubrificante é superior a dimensão da rugosidade média das superfícies (fig. 3.2). Este regime de lubrificação é definido para;

$$
3 \leq \lambda \leq 10
$$

sendo que, 10 é um limite superior proposto, pois, geralmente é difícil estabelecer um limite superior que apresente tais dimensões.

Neste regime o filme lubrificante separa completamente as duas superficies, logo, o contato entre as asperezas e o desgaste destas superfícies são despreziveis. Neste caso haverá apenas atrito viscoso entre as superficies deslizantes, pois, a carga cisalhante é transferida totalmente para o fluido.

Este regime depende das propriedades físicas e tribológicas do sistema e, portanto, neste regime se desconsidera completamente o efeito da rugosidade no escoamento do fluido, desta forma ele apresenta um coeficiente de atrito baixo, por uma faixa de valores maior que o regime misto; definindo-o então como o regime mais adequado em muitas situaçōes $[51,52]$.

Neste trabalho, analisamos um mancal radial sob o regime de lubrificação hidrodinâmico, dai, pode-se afimar que:

$$
h>3 . R_{a}
$$




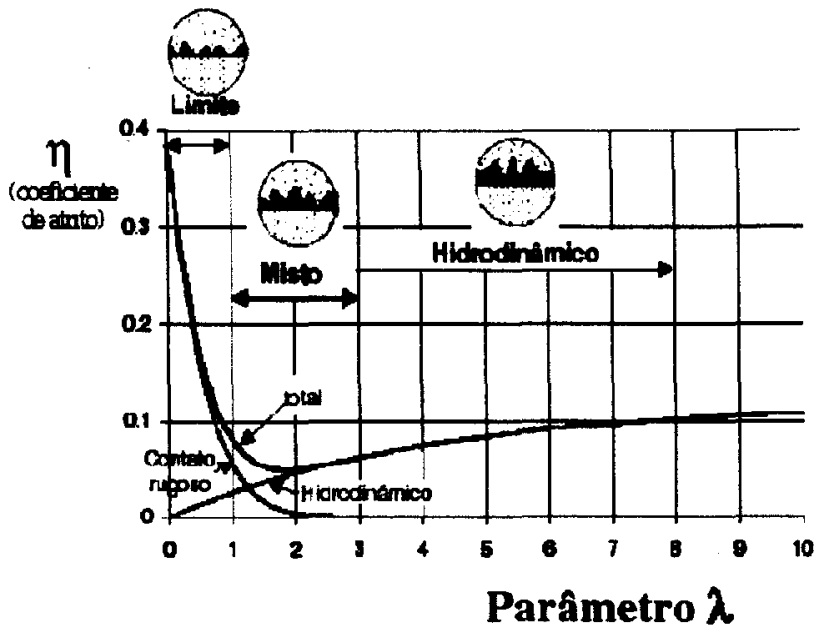

Figura 3.2: Regimes de lubrificação segundo o parâmetro $\lambda$ [51].

\subsection{Análise da lubrificação em um mancal radial}

A eficiência da lubrificação em um mancal radial depende dos parâmetros operacionais deste componente, como a espessura minima $\left(h_{o}\right)$ do filme lubrificante. Neste trabalho utilizamos a capacidade de carga para analisar a eficlência da lubrificação, pois há uma relação da espessura minima com este parâmetro.

\subsubsection{A espessura minima do filme lubrificante}

Um mancal radial é especificado pelos seus parâmetros operacionais, que geralmente são divididos em duas classes distintas: os parâmetros conhecidos, adotados pelo projetista, e os parâmetros dependentes, determinados a partir destes.

\section{Os parâmetros conhecidos såo:}

1. A rotação do eixo $\left(A=\frac{\omega}{2 \pi}\right)$.

2. A viscosidade do fluido $(\mu)$. 
3. As dimensões do mancal: Raio do eixo $(R)$, a folga radial (c) e o comprimento do mancal $(L)$.

4. A carga aplicada no eixo do mancal ${ }^{2}\left(W_{A}\right)$.

5. A pressão aplicada $\left(P_{A}=\frac{W_{A}}{L .2 . R}\right)$.

\section{Os parâmetros dependentes são:}

1. O coeficiente de atrito.

2. O acréscimo de temperatura.

3. A potência de acionamento.

4. A vazão do lubrificante.

5. A espessura minima, relacionada a força de sustentação $\left(h_{o}\right)$.

A eficiência do processo de lubrificação em um mancal radial, sob o regime hidrodinâmico, está relacionada com os parâmetros dependentes deste elemento de máquina $[1,50]$.

A espessura minima do fluido, pode ser utilizada para especificar tal eficiência, afinal, aumentando este parâmetro evita-se o atrito seco e melhora-se a lubrificação no mancal. A espessura minima pode ser definida utilizando-se o fator de excentricidade, determinado pelo equilibrio das forças presentes no mancal.

Geralmente, pode-se distinguir basicamente três forças: a força gravitacional, a carga aplicada ao fluido lubrificante pelo eixo devido sua rotação e a força de sustentação do fluido lubrificante devido sua compressão, que será especificada adiante.

O equilibrio destas forças produz uma excentricidade $e$ no eixo do mancal, definida como a distância entre seu centro e o do alojamento (distância AE na

\footnotetext{
${ }^{2}$ A soma das forças aplicadas no eixo.
} 


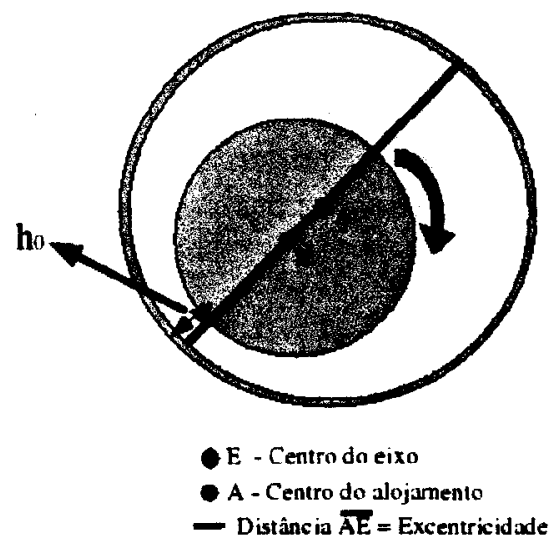

Figura 3.3: Mancal radial girando no sentido horário, provocando o deslocamento do eixo para a esquerda, na figura.

figura 3.3). A folga radial $c$ é definida como a diferença entre os raios interno do alojamento e externo do eixo. O fator de excentricidade $\epsilon$ é definido pela razão (adimensional) entre eles:

$$
\epsilon=\frac{e}{c}
$$

Após a determinação do fator de excentricidade, define-se a distância minima $h_{0}$ entre o eixo e o alojamento pela expressão:

$$
h_{0}=c .(1-\epsilon)
$$

Em geral, a determinação deste fator não é trivial, devido a dinâmica do fluido. Então, para determinar a espessura mínima, normalmente, utlliza-se a relação (fig. 3.4) entre esta e o número de Sommerfeld $\left(N_{S}\right)$, que será obtido utilizando os parâmetros (conhecidos) pré-definidos pelo projetista e, que é definido por:

$$
N_{S}=\frac{\mu \cdot A}{P_{A}} \cdot\left(\frac{R}{c}\right)^{2}
$$




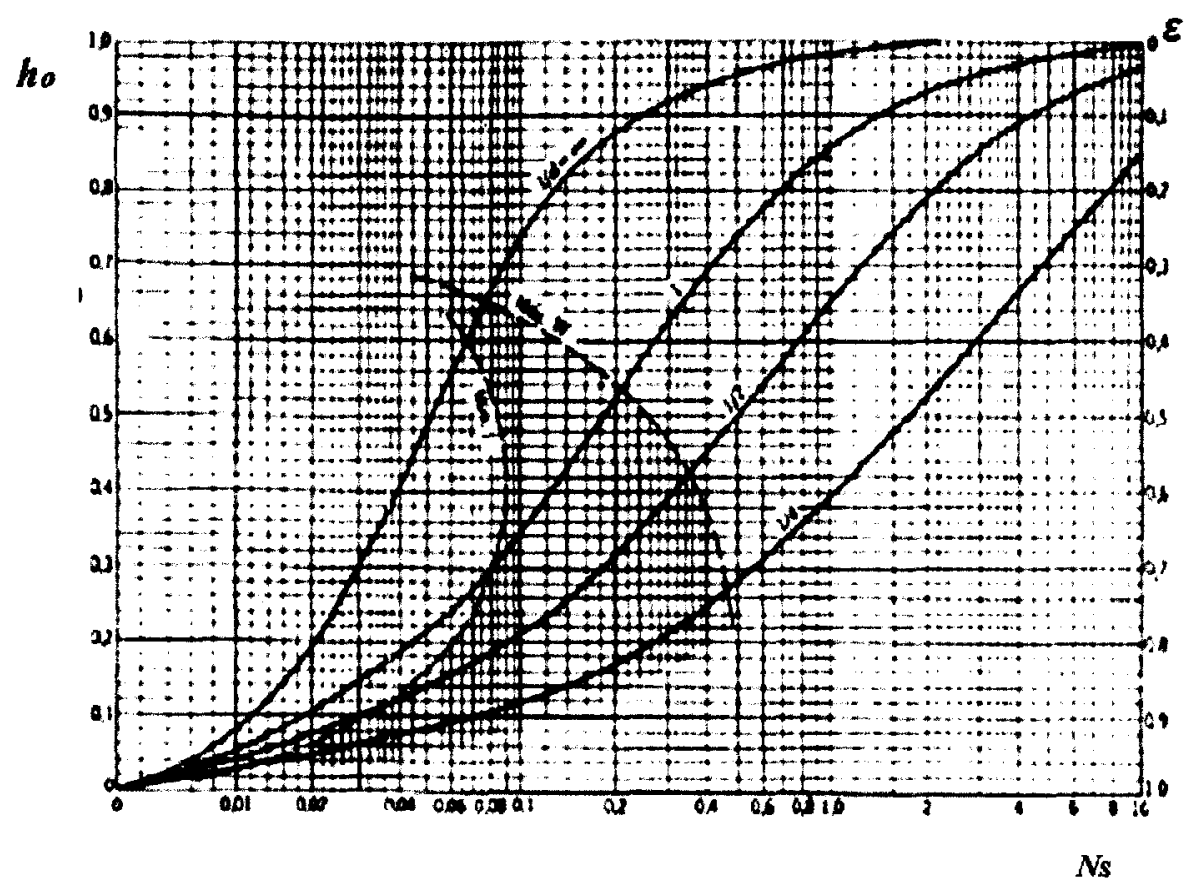

Figura 3.4: Diagrama que apresenta a relação de $N_{S} \operatorname{com} h_{o}$

Utilizando a figura 3.4 é possivel determinar o valor de $h_{o}$ sendo $N_{S}$ conhecido. Portanto, ao se projetar um mancal radial, deve-se ajustar os parâmetros conhecidos, de forma que a espessura minima do filme não se anule, afinal, isto implica em uma lubrificação hidrodinâmica eficaz [1, 50].

\subsubsection{A auto-pressurização em mancais radiais}

Modificações no campo de pressão do fluido lubrificante alteram a força de sustentação (capacidade de carga) e, conseqüentemente, a espessura minima deste fluido, o que torna pertinente uma análise do perfil deste campo de pressão [1].

Históricamente, Beauchamp Tower foi o primeiro a analisar o perfil do campo de pressão em um mancal. Ele percebeu que a medida que o eixo do macal começava a girar, o óleo era esguichado para fora do mancal através de 
um furo no alojamento, indicando assim a presença de altíssimas pressões hidrodinâmicas no lubrificante[2].

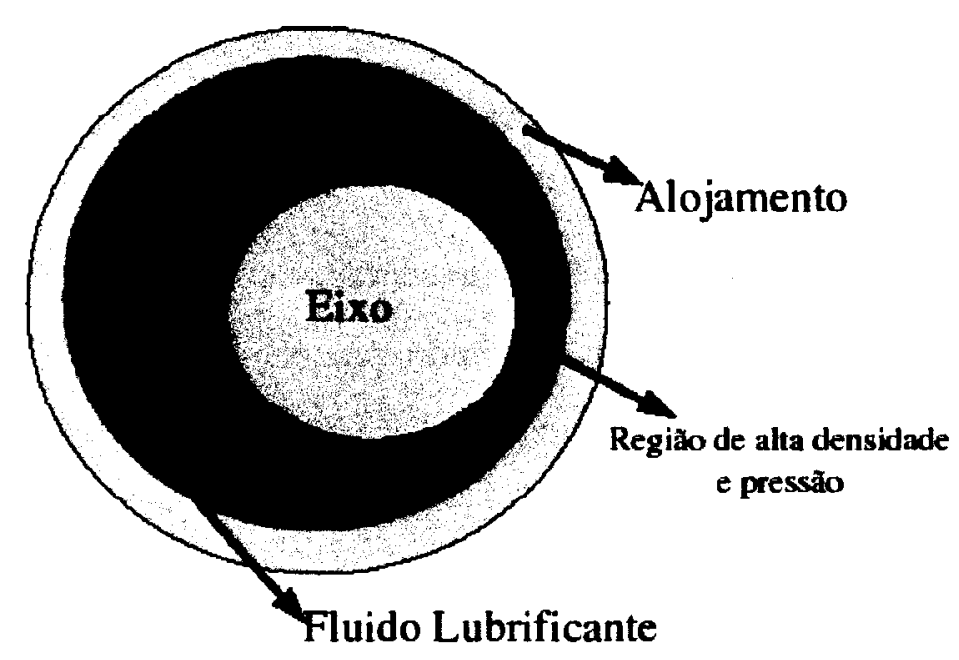

Figura 3.5: O óleo é esguichado através do furo no alojamento devido a pressão criada pela rotação do eixo (sentido anti-horário).

Se não houvesse um furo, o fluido seria comprimido entre o eixo e o alojamento, produzindo uma altíssima pressão hidrodinâmica na região convergente (fig. 3.5), aumentando assim sua densidade $e$, conseqüentemente, a pressão nesta região, conforme indica a relação;

$$
\Delta P=\beta \frac{\Delta \rho}{\rho}
$$

onde $\beta$ é o fator de compressibilidade e $\Delta \rho$ é a diferença de densidade associada a variação de pressão $\Delta P$.

O fluido ao ser comprimido exerce uma reação sobre as superfícies (do eixo e alojamento) tendendo a separá-las. Este efeito, denominado autopressurização, é essencial no processo de lubrificação, pois ele é responsável. em parte, pela força de sustentação que define a espessura minima $\left(h_{o}\right)$ do 
lubrificante [1].

O principio do efeito de auto-pressurização está ilustrado na fígura 3.6, na qual apresenta-se o perfil do campo de pressão em um fluido que escoa por um canal convergente e divergente. Este é um modelo razoável para o escoamento do fluido lubrificante no mancal radial, devido sua geometria cilíndrica.

O perfil do campo de pressão apresentado na figura 3.6 foi determinado pela equação de Reynolds, considerando uma pressão constante nas extremidades do canal. Além disso, este perfil deve ser ajustado conforme estabelece a condição de Sommerfeld: todas as pressões negativas devem ser anuladas ${ }^{3}$.
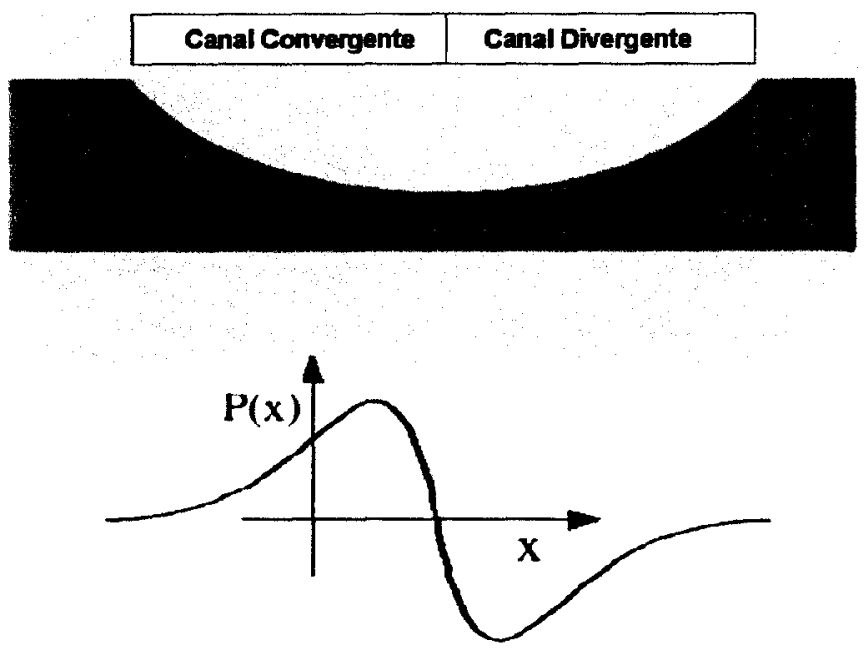

Figura 3.6: Campo de pressão em um fluido escoando por um canal convergente e divergente.

Esta condição é necessária e suficiente para evitar o anulamento da força de sustentação e confirmar o efeito de auto-pressurização, dai, a força de sustentação (capacidade de carga) é definida pela integral (2.8) da pressão do fluido sobre a área atuante e logo, esta força se cancelaria devido o caráter

\footnotetext{
${ }^{3}$ Esta condição justifica-se devido ao efeito da cavitação (Anexo 6.1), como será discutıdo no quarto capitulo.
} 
simétrico da distribuição (campo) de pressão, caso não se adotasse a condição de Sommerfeld [1].

Deve-se ressaltar que, o campo de pressão $\left(P_{i, j}\right)$ é definido numericamente a partir da equação de Reynolds, então, a força de sustentação (capacidade de carga) deve ser representada pela expressão (2.15):

$$
W=\sum_{i=0}^{N} \sum_{j=0}^{N} P_{i, j} . \Delta x . \Delta y
$$

A capacidade de carga está relacionada com a espessura minima do fluido lubrificante, e ela será definida como um parâmetro da eficiência do processo de lubrificação. Portanto, uma alteração num parâmetro operacional do mancal que aumente o valor da capacidade de carga, deverá melhorar a eficiência do processo de lubrificação [7].

\subsection{O efeito da texturização na lubrificação do mancal}

A presença de texturas no eixo de um mancal altera o campo de pressão do fluido, pois estas micro-cavidades desempenham um papel de pequenos canais convergentes e divergentes no escoamento do fluido. Em vista disto, a capacidade de carga total $(W)$ será definida pela capacidade de carga ligada a auto-pressurização $\left(W_{P}\right)$ adicionada a capacidade de carga relacionada à texturização $\left(W_{T}\right)$, ou seja:

$$
W=W_{P}+W_{T}
$$

Contudo, a influência das micro-cavidades na capacidade de carga $\left(W_{T}\right)$ relacionada a textura, pode ser abordada por um modelo simplificado de duas placas deslizantes. Isto se deve a dimensão do mancal ser superior a destas micro-cavidades, tornando irrelevante a curvatura cilindrica deste componente, conforme está ilustrado na figura 3.7. 


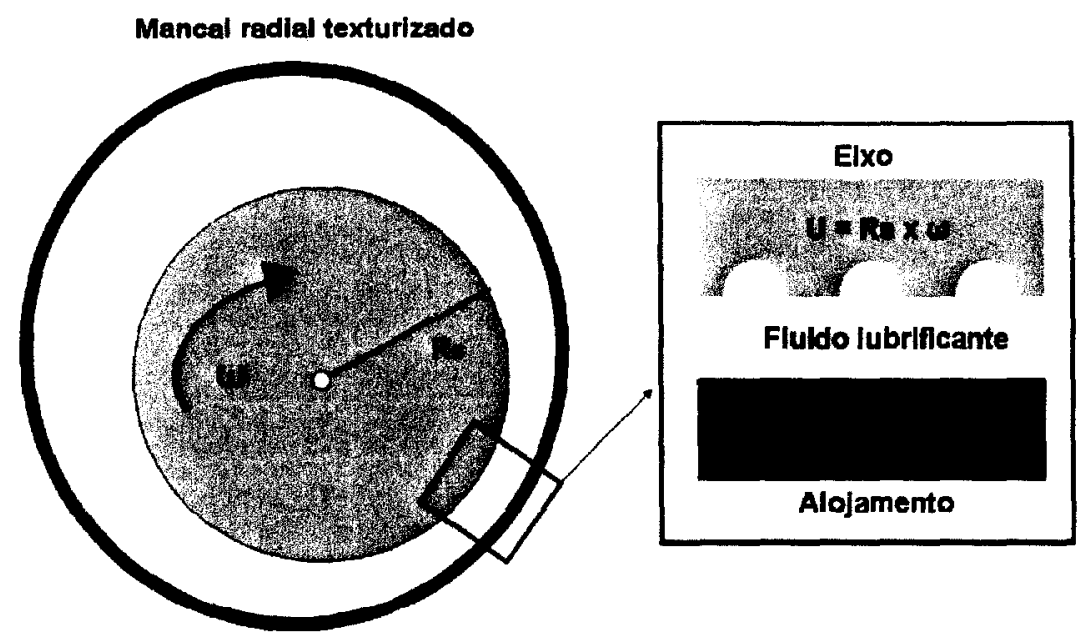

Figura 3.7: Representação em detalhe da região estudada no mancal texturizado, onde, $R_{S}$ é o raio do eixo, que gira com uma velocidade angular $\omega$.

De acordo com trabalhos recentes $[29,36]$ o campo de pressão, conforme esta configuração, apresentará uma deformação caso haja interação entre as cavidades. Entretanto, neste trabalho, supõe-se uma distribuição de pressão periódica, desconsiderando interações entre as cavidades, como está ilustrado na figura 3.8 pela linha vermelha.

Utilizando esta configuração para a distribuição de pressão, sem interação entre as células, pode-se definir uma relação (unidimensional) entre a capacidade de carga $\left(W_{T}\right)$ com a pressão máxima local $\left(P_{m}\right)$ de uma única célula;

$$
W_{T}=N * R_{1} * P_{m}
$$

sendo $R_{1}$ o comprimento da célula e $N$ o número de células.

Desta maneira, o efeito de alterações nas caracteristicas das cavidades sobre a capacidade de carga $\left(W_{T}\right)$, pode ser definido analisando-se uma única célula. Estas alterações deverão modificar apenas a pressão máxima local 
$\left(P_{m}\right)$ na equaçāo $(3.6)[13,17]$.

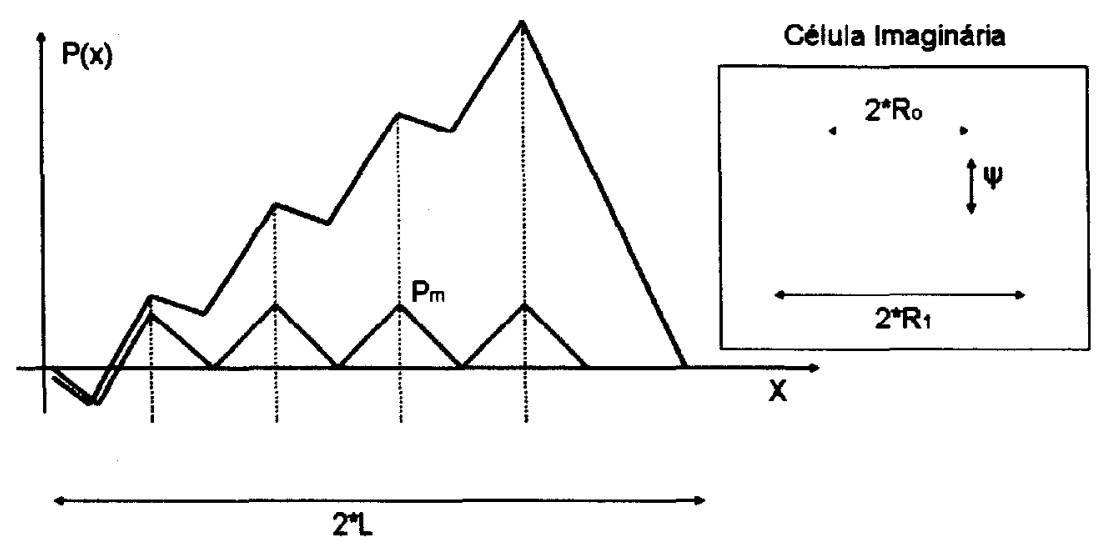

Figura 3.8: Distribuição de pressão para um eixo parcialmente texturizado (linha azul) e totalmente texturizada (linha vermelha).

Por fim, neste trabalho, a forma e as dimensões destas micro-cavidades serão otimizadas utllizando-se um modelo definido por um única célula. Esta otimização implica na maximização da capacidade de carga [13] ou da pressão local [17] desta célula. A densidade superficial da textura, não pode ser analisada utilizando este modelo, pois ela está relacionada a todos os parâmetros da equação (3.6).

\subsection{O processo texturização superficial}

A texturização superficial pode ser realizada por diversos métodos [24], porém o laser é um equipamento que propicia precisão e agilidade, devido suas propriedades físicas como a coerência do feixe da luz laser, tornando este processo econômico e tecnologicamente viável. 
Para que se possa compreender e controlar a texturização superficial, a fim de obter uma lubrificação mais eficaz por meio da otimização das microcavidades, deve-se primeiramente compreender como funciona o processo de ablação, pois controlando o processo de ablação, pode-se controlar a forma e as dimensōes das micro-cavidades.

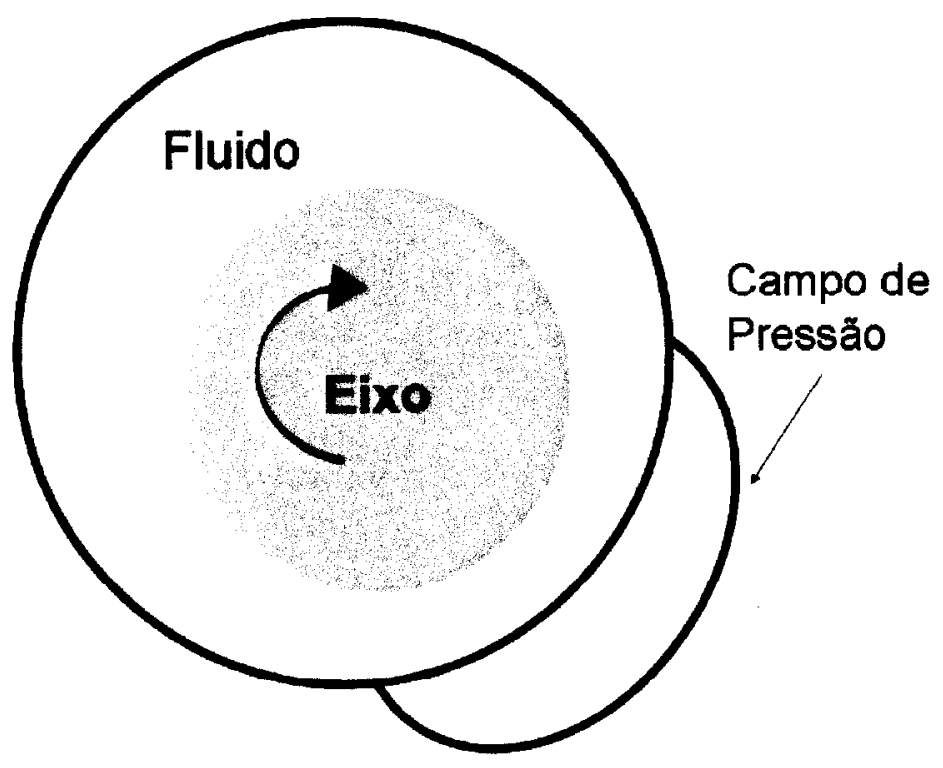

Figura 3.9: Campo de pressão em um mancal radial, devido ao efeito de autopressurização.

\section{Analisando o processo de ablação}

Sabe-se que o laser produz micro-cavidades removendo o material por ablação, entretanto, este processo gera efeitos térmicos que podem levar a alteraçōes das propriedades físicas do material; alteraçōes que podem ser interessantes conforme a aplicação do componente texturizado. Deste modo, torna-se pertinente conhecer os principios do processo de ablação a laser $[53,54]$.

Este processo depende tanto das propriedades fisicas (térmicas e óticas) 
do material como das características do laser: comprimento de onda, duração do pulso, intensidade, etc. Recentemente estudos foram realizados com o propósito de correlacionar a taxa de ablação dos materiais com as características do laser, a fim de controlar o processamento superficial de materiais (perfuração, texturização, etc.) $[55,56]$.

Quando a radiação laser incide num material ela pertuba seus elétrons livres (metais) ou sua rede iônica (isolantes), de maneira inversa ao efeito de Bremsstrahlung ${ }^{4}$. Esta pertubação se converte em fônons que se propagam rapidamente $(t e m p o \simeq p s)$ pelo material. Caso a energia da radiação seja muito alta, ocorrerá a fusão e evaporação do material subitamente [55].

A energia $\left(E_{I}\right)$ de um feixe de laser, que incide sobre a superficie de um material, não é absorvida $\left(E_{A}\right)$ completamente. Uma parcela desta radiação é refletida, $E_{R}$, enquanto outra é transmitida, $E_{T}$. A conservaçāo de energia do sistema define que:

$$
E_{I}=E_{A}+E_{R}+E_{T}
$$

Para o processo de ablação, a parcela da energia absorvida $\left(E_{A}\right)$ é a que tem maior relevância. Considerando que a energia absorvida irá aumentar localmente a temperatura, levando a fusão e posteriormente a evaporação, pode-se estabelecer que;

$$
E_{A}=\rho .\left(c .\left(\Delta T_{f}+\Delta T_{v}\right)+L_{f}+L_{v}\right) \cdot \frac{\pi \cdot a^{2} \cdot z}{4}
$$

tal que $a$ e $z$ são as dimensões da região em que fol removido material (cavidade); o diâmetro e a profundidade respectivamente. As outras variáveis são características do material: $c$ é o calor específico, $\rho$ é a densidade,$L_{f}$ é o calor latente de fusão, $L_{v}$ é o calor latente de evaporação [53].

O termo $\Delta T_{f}=T_{f}-T_{0}$, representa a variação da temperatura ambiente $\left(T_{0}\right)$ até a temperatura de fusão $\left(T_{f}\right)$ e, o termo $\Delta T_{v}=T_{v}-T_{f}$, a variação da tem-

\footnotetext{
${ }^{4}$ Efeito ligado a produçāo de Raio-X.
} 
peratura de fusão até a temperatura de evaporação $\left(T_{v}\right)$. A partir destas informações, pode-se determinar a energia necessária para produzir uma cavidade cujas dimensões sejam pré-defindidas.

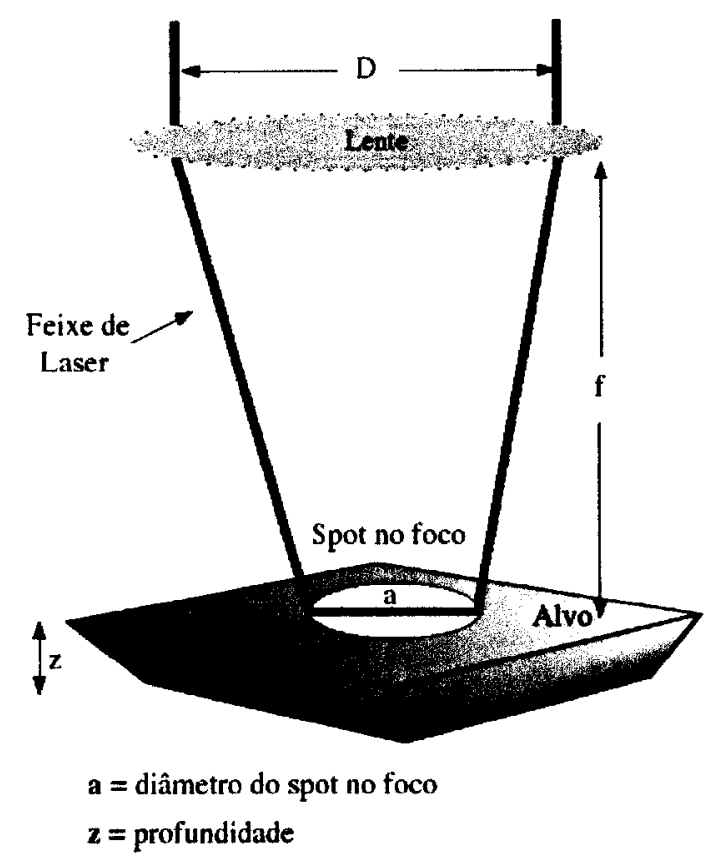

Figura 3.10: Incidência do feixe de laser no material (alvo).

Definindo a potência da radiação laser $P$ como a variação da energia absorvida pelo material $\Delta E_{A}$ em função do tempo de exposição $\Delta t$;

$$
P=\frac{\partial E_{A}}{\partial t}=\frac{\rho \cdot \pi \cdot a^{2}}{4}\left(c \cdot\left(\Delta T_{f}+\Delta T_{v}\right)+L_{f}+L_{v}\right) \cdot V
$$

pode-se determinar o valor da velocidade da frente de evaporação $V$ rearranjando a equaçāo anterior:

$$
V=\frac{4 . P}{\rho . \pi \cdot a^{2} \cdot\left(c \cdot\left(\Delta T_{f}+\Delta T_{v}\right)+L_{f}+L_{v}\right)}
$$

A taxa de ablação $A$ pode ser definida como a velocidade da frente de evaporação dividida pela duração do pulso $\tau_{p}$ (como unidade de tempo). 


$$
A=\frac{V}{\tau_{p}}
$$

Determinando $A$ para alguns materiais pode-se estimar o perfil e as dimensões da micro-cavidades produzidas no processo de texturização [53]. 


\section{Capitulo 4}

\section{Resultados e discussão}

O processo de lubrificação em mancais radiais pode ser abordado por uma versão adimensional da equação de Reynolds. A solução desta equação será determinada pelo algoritmo desenvolvido neste trabalho, o qual a precisão e estabilidade serão analisadas. A partir desta solução determina-se o efeito que as caracteristicas das micro-cavidades exerce sobre a capacidade de carga. Desta forma definimos a forma, densidade e dimensões para estas micro-cavidades, conforme a maximização deste parâmetro e conseqũentemente da eficiência da lubrificação.

\subsection{Adimensionalização da equação de Reynolds}

A adimensionalização da equação de Reynolds não altera sua soluçāo, em vista disto, será determinada esta versão a partir da equação de Reynolds bidimensional (2.7);

$$
\frac{\partial}{\partial x} \cdot\left(h^{3} \cdot \frac{\partial p}{\partial x}\right)+\frac{\partial}{\partial y} \cdot\left(h^{3} \cdot \frac{\partial p}{\partial y}\right)=6 \cdot \mu \cdot U \cdot \frac{\partial h}{\partial x}
$$

que representa o escoamento de um fluido entre duas placas deslizantes, assim como o modelo descrito na seção anterior.

Convém ressaltar que a espessura do filme lubrificante será representada pela seguinte expressão; 


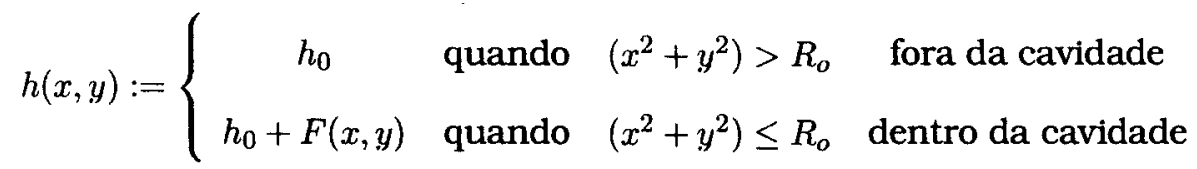

tal que, $h_{0}$ é a espessura mínima do filme lubrificante, $2 . R_{o}$ é o diâmetro de abertura da cavidade e $F(x, y)$ a função que descreve a forma desta. Ainda. deve-se salientar que a equação de Reynolds segundo estas condições é uma EDP eliptica.

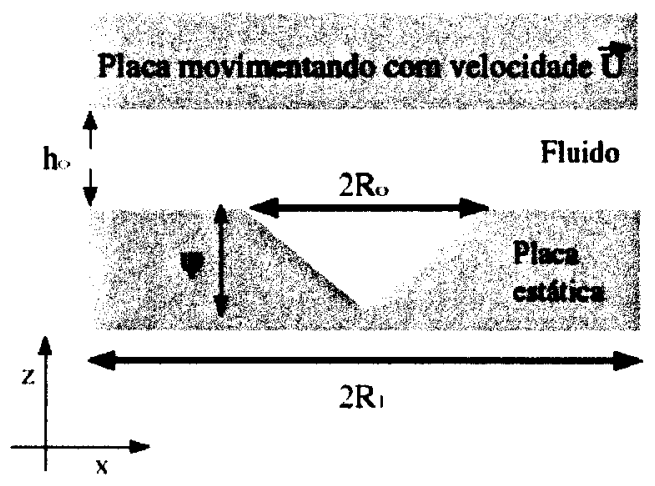

Figura 4.1: Duas placas deslizantes, sendo que uma esta texturizada.

Logo, utilizando as seguintes transformações de variáveis;

$$
X=\frac{x}{R_{o}} \text { e } Y=\frac{y}{R_{o}}
$$

obtem-se a equação de Reynolds adimensional;

$$
\frac{\partial}{\partial X} \cdot\left(H^{3} \cdot \frac{\partial P}{\partial X}\right)+\frac{\partial}{\partial Y} \cdot\left(H^{3} \cdot \frac{\partial P}{\partial Y}\right)=\frac{\partial H}{\partial X}
$$

acarretando na seguinte relação entre as pressōes;

$$
P=\frac{p}{\Lambda}
$$


sendo que $\Lambda=\frac{6 . \mu . U}{R_{0}}$.

Contudo, a equação (4.4) justifica a relação linear do campo de pressão com a viscosidade e velocidade, como foi apresentado na seção anterior, pois, a partir desta equação pode-se expressar:

$$
p \simeq \alpha . P
$$

Outra relação importante é definida durante a elaboração da equação adimensional;

$$
H(X, Y)=\frac{h(x, y)}{R_{0}}
$$

ou seja;

$$
H(X, Y)=\left\{\begin{array}{cc}
\gamma & \text { quando }\left(X^{2}+Y^{2}\right)>1 \\
\gamma+\Psi * F(X, Y) & \text { quando }\left(X^{2}+Y^{2}\right) \leq 1
\end{array}\right.
$$

Nesta expressão, $\gamma=\frac{h_{0}}{R_{0}}$ é o parâmetro utilizado para analisar o efeito do diâmetro $\left(2 . R_{o}\right)$ da microcavidade no campo de pressão, pois, como a folga radial minima $\left(h_{o}\right)$ é um valor prenunciado (Cap. 3), a variação deste parâmetro implica numa variação do diâmetro, afinal, o diâmetro não pode ser alterado diretamente nas simulaçōes realizadas, conforme indica esta abordagem adimensional.

O fator $\Psi$ é acrescentado na expressão anterior para representar o efeito da profundidade, da microcavidade, na solução da equação e conseqũentemente na capacidade de carga.

A partir de outra razão adimensional:

$$
\xi=\frac{R_{1}}{R_{0}}
$$

pode-se redefinir as condiçōes de contorno ${ }^{1}$ em termos deste novo parâmetro

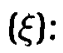

$$
P(x, y= \pm \xi)=P_{a t m}=c t e
$$

\footnotetext{
${ }^{1}$ A pressão atmosférica foi condicionada como zero para simplificar os cálculos, afinal, qualquer valor constante que ela assumir não modifica o resultado final.
} 
e também, determinar a densidade superficial $S$ utilizando-o:

$$
\begin{gathered}
S=\frac{\pi \cdot R_{0}{ }^{2}}{4 \cdot R_{1}{ }^{2}}=\frac{\pi}{(2 . \xi)^{2}} \\
\xi=\frac{1}{2} \sqrt{\frac{\pi}{S}}
\end{gathered}
$$

Portanto, este parâmetro $(\xi)$ será utilizado para analisar o efeito da densidade no campo de pressão e conseqüentemente na capacidade de carga.

Enfim, na tabela a seguir (4.1), apresenta-se um resumo dos parâmetros adimensionais relacionados com as características da cavidade, ou seja, as características que estes parâmetros determinam durante as simulações.

Tabela 4.1: Relação dos parâmetros utilizados no algoritmo com as caracteristicas da microcavidade.

\begin{tabular}{|c|c|c|c|}
\hline Parâmetro & Caracteristica & Parâmetro & Característica \\
\hline \hline$\gamma$ & Diâmetro & $\Psi$ & Profundidade \\
\hline$\xi$ & Densidade & $F(X, Y)$ & Forma \\
\hline
\end{tabular}

\subsection{A precisão e estabilidade do algoritmo}

Como foi enunciado, a solução numérica de uma EDP apresenta uma precisão e estabilidade devido aos erros computacionais, apresentados anteriormente. Para analisar a precisão de um algoritmo, pode-se contrastar sua solução numérica com uma solução exata, conhecida na literatura [7]. Então, na figura 4.2 a solução numérica (1024 pontos) obtida pelo algoritmo apresentado no anexo 6.2, foi confrontada com uma solução exata apresentada na literatura [7]. Observando tal figura, pode-se afirmar que a solução numérica apresenta uma precisão bastante razoável, indicando que o nosso algoritmo é confiável. 
Entretanto, esta solução numérica apresenta uma instabilidade devido aos erros computacionais, logo, para evitar que esta instabilidade afete a precisão desta solução, geralmente são utilizadas ferramentas da estatística, como será enunciado a seguir.

A estabilidade de um algoritmo computacional depende de diversos parâmetros devido aos tipos de erros possiveis, como fol apresentado no segundo capitulo. Analisando dois erros em especial: computacional e de discretização; pode-se afirmar que a medida que se aumenta o número de pontos em uma malha diminui-se o erro de discretização, no entanto, isto aumenta o erro computacional, pois, para cada ponto acrescentado surge também uma nova equação.

Em vista disto, a medida que se refina a malha deve-se analisar a região de menor oscilação da solução, a fim de reduzir ao máximo o erro geral (fig. 4.3). Um valor médio calculado a partir dos valores desta região, mais estável, é definido como o valor mais próximo da solução exata.

Os valores da capacidade de carga que serão apresentados a seguir, foram determinados pelo valor médio calculado no intervalo, referente ao tamanho da malha, mais estável. Desta forma o valor obtido apresenta um desvio padrão pequeno, estabelecendo assim uma grande confiança no resultado teórico.

Observando a figura 4.3, nota-se que a solução atinge uma estabilidade a partir de $N=20$ (441 pontos), convergindo para um valor médio. Estabelecemos então, neste caso, que o valor médio da capacidade de carga deve ser calculado a partir deste tamanho $(\mathrm{N}=20)$, definido como o valor mínimo de $N$. O valor máximo de $N$ deve ser escolhido antes que apareça oscilaçōes devido a erros computacionais, no caso apresentado (fig. 4.3) pode-se afirmar que $N=60$ é um valor máximo razoável. 


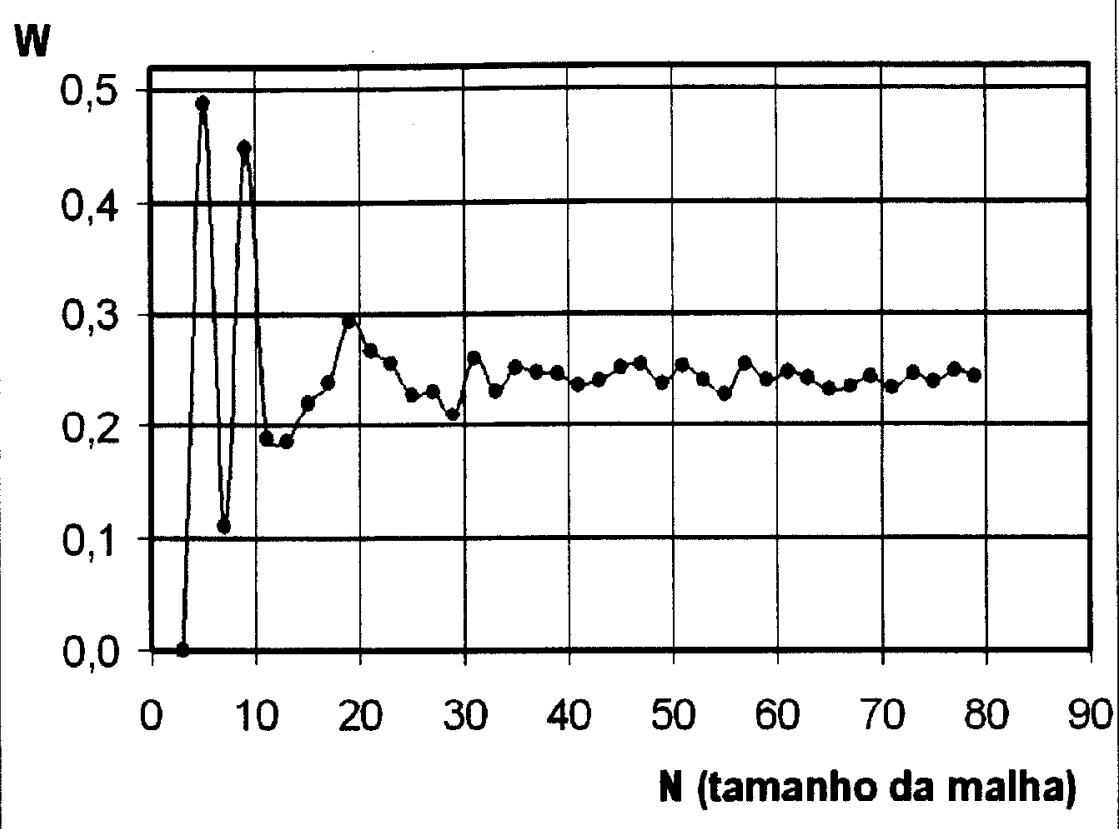

Figura 4.2: Determinação da capacidade de carga para uma cavidade cônica, conforme refina-se a malha. Definindo, $\Psi=1, \gamma=2.58$ e $\xi=2,64$, como os parâmetros persentes no algoritmo (Anexo 6.2).

\subsection{Análise das alterações no campo de pressão}

A determinação do efeito de micro-cavidades superficiais no campo de pressão do fluido em um mancal radial, conforme o modelo descrito na seção anterior, é relevante para compreensão do processo de lubrificação.

Considerando um modelo com duas placas deslizantes sem textura, separadas por um fluido, tem-se que a função $F(X, Y)$ se anula tornando a equação de Reynolds na equação de Laplace;

$$
\frac{\partial^{2} P}{\partial X^{2}}+\frac{\partial^{2} P}{\partial Y^{2}}=0
$$

cuja solução numérica, deve ser representada por uma superficie plana, como mostra a figura 4.3 .

Ao se acrescentar uma cavidade cônica na placa inferior (figura 4.1), cuja 

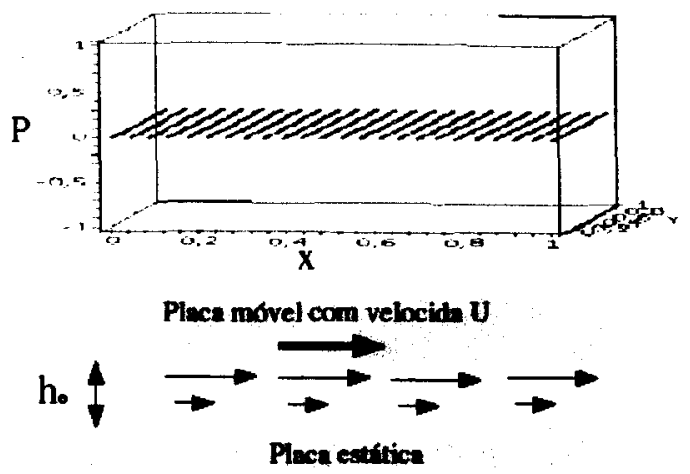

Figura 4.3: Solução numérica (576 pontos) para um fluido escoando entre duas placas planas.

a forma é definida pela função:

$$
F(X, Y)=\exp \left(-2 *\left(X^{2}+Y^{2}\right)\right)
$$

A solução numérica da equação de Reynolds, supondo esta configuração, está representada graficamente na figura 4.4. Vale ressaltar que estas soluções apresentam os valores discretos $P_{i, j}$ que representam a pressão num ponto $(i, j)$ da malha (dominio da EDP).

Analisando este modelo fisicamente, pode-se deduzir que ocorre uma redução na densidade do fluido quando este se aproxima da cavidade (região divergente), pois nesta região há um aumento do espaçamento entre as placas. Por outro lado, ocorrerâ um acúmulo de matéria na borda oposta da cavidade (região convergente), proporcionando uma alta densidade (pressão) nesta região. Este efeito conjunto do canal divergente com o convergente justifica o carater da distribuição de pressão apresentado na figura 4.4.

Comparando as figuras 4.3 e 4.4, nota-se que a cavidade provoca uma pertubação simétrica no campo de pressão, decrescendo suavemente a medida que se distancia do ponto de pertubaçāo, como foi prenunciado no capítulo 
2 , onde foi afirmado que uma simples pertubação na região $\Omega$, domínio da equação elíptica em estudo, se propagaria suavemente por toda esta região.

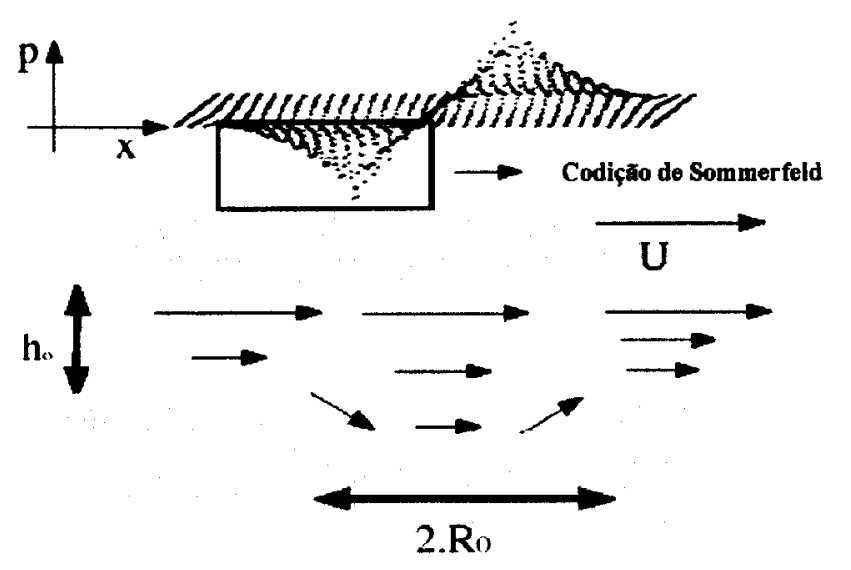

\begin{tabular}{|l|l|}
\hline Kegiăo Livergente & Keglao Convergente \\
\hline
\end{tabular}

Figura 4.4: Solução numérica (576 pontos) para um fluido escoando entre duas placas com uma cavidade.

Em ambos os casos, para a determinação da solução, adota-se a pressão como zero nas bordas, logo as condições de contorno podem ser definidas pela expressão:

$$
P( \pm \xi, Y)=P(X, \pm \xi)=0
$$

A (semi) condição de Sommerfeld estabelece que qualquer pressão negativa deve-se anular, produzindo uma assimetria na ditribuição de pressão, como ilustra a figura 4.4 [1]. Esta condição é justificada pelo efeito de cavitação (Anexo 6.1), que estabelece um limite inferior para a pressão; desta forma evita-se a anulação da capacidade de carga relacionada a cavidade.

Deve-se salientar que esta condição não é a mais adequada ${ }^{2}$ segundo o efeito de cavitação, entretanto, ela favorece os cálculos computacionais por

\footnotetext{
${ }^{2}$ Guando deseja-se uma maior precisāo nos resultados físicos utiliza-se a condiçāo de Reynolds.
} 
sua simplicidade, evitando erros numéricos sem comprometer consideravelmente o resultado físico do problema.

Portanto, ao se acrescentar micro-cavidades na superficie de duas placas deslizantes, separadas por um fluido, produz-se uma carga (força) adicional neste fluido devido o efeito coletivo destas micro-cavidades no campo de pressão. Este efeito auxilia o mecanismo de lubrificação por complementar a capacidade de carga total, evitando o contato (atrito seco) entre as superficies atritantes.

\subsection{As características ideais para as cavidades}

A partir dos parâmetros apresentados na tabela 4.1, pode-se determinar as caracteríticas ideais para as cavidades, definindo um padrão ideal de texturização superficial ${ }^{3}$, conforme a otimização capacidade de carga relacionada a textura (Cap. 3). Durante a determinação destas características, em cada simulação, varia-se apenas o parâmetro analisado, mantendo os outros fixos.

A primeira caracteristica a ser determinada é a forma geométrica da cavidade, pois, em seguida, a profundidade e o diâmetro serão determinados utilizando apenas esta forma. Para a determinaçāo da densidade superficial propõe-se um modelo mais elaborado, analisando-se uma placa texturizada.

\subsubsection{A forma e as dimensões da cavidade}

Utilizando as equações (4.3) e (4.5) em conjunto com as condições de contorno (4.7). determina-se a forma e as dimensões da cavidade, por meio de simulações do modelo proposto anteriormente (Cap. 3).

\section{A Forma}

Para variar a forma da cavidade, basta redefinir a função $F(X, Y)$ na

\footnotetext{
${ }^{3} \mathrm{~A}$ forma, a profundidade, a densidade superficial e o diâmetro da cavidade.
} 

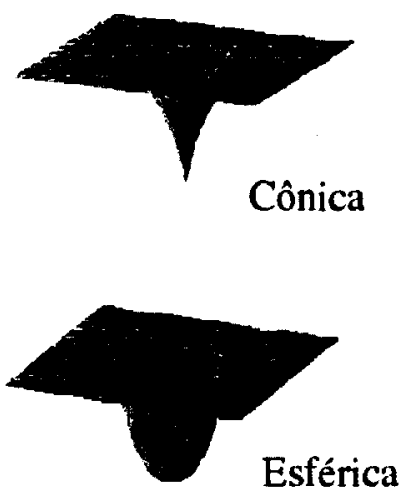
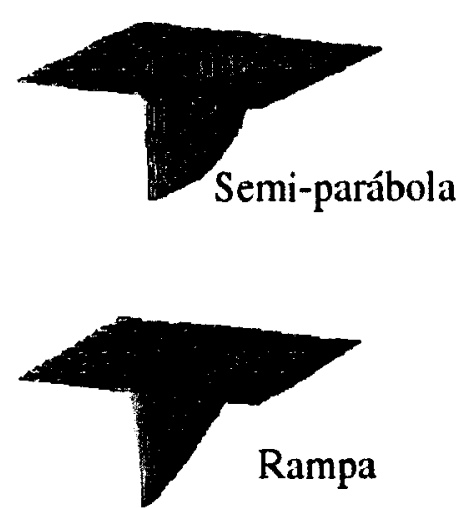

Figura 4.5: Representação tridimensional das quatro formas estudadas.

equação (4.5), porque esta função representa este parâmetro da cavidade (Tabela 4.1). A seguir, apresenta-se os resultados de simulações realizadas variando-se $F(X, Y)$ (tabela 4.2), com quatro formas diferentes propostas para a cavidade: esférica, cônica, semi-parabólica e cilíndrica com rampa, como a figura 4.5 apresenta.

Conforme os valores apresentados na tabela 4.2, nota-se que a forma mais eficiente é a cilíndrica com rampa, seguida pela semi parabólica.

Deve-se salientar que, para o cálculo destas capacidades de carga, foram fixados os seguintes valores para os outros parâmetros do algoritmo: $\gamma=2.5$, $\Psi=1, \xi=2.5$, indicando as mesmas caracteristicas para as microcavidades com formas diferentes.

Outras simulações para avaliar a forma das cavidades foram realizadas, alterando os parâmetros que foram anteriormente fixados; entretanto, a ordem apresentada na tabela 4.2 permanece, definindo assim a forma cilíndrica com rampa como a mais eficiente para a lubrificação.

Analisando os valores na tabela, pode-se concluir que, a capacidade de carga é maximizada quando a forma proposta apresenta uma variação (queda) 
Tabela 4.2: Valores médios da capacidade de carga, para as quatro formas propostas, com seus respectivos desvios padrões.

\begin{tabular}{|c|c|c|}
\hline Forma & $\Psi * F(X, Y)$ & Capacidade de $\operatorname{Carga}^{4}\left(W_{T}\right)$ \\
\hline \hline Rampa cilindrica & $\frac{\Psi}{2} \cdot(1-X)$ & $0,1016 \pm 0,0025$ \\
\hline Semi-parábola & $\frac{\Psi}{4} \cdot\left(X^{2}+2 X-3\right)$ & $0,0953 \pm 0,0028$ \\
\hline Esférica & $\Psi \cdot \sqrt{1-X^{2}-Y^{2}}$ & $0,0326 \pm 0,0065$ \\
\hline Cónica & $\Psi \cdot \exp \left(-2 \cdot \sqrt{\left(X^{2}+Y^{2}\right)}\right)$ & $0,0103 \pm 0,0002$ \\
\hline
\end{tabular}

abrupta no principio da cavidade ${ }^{5}$, definindo desta forma, que o mesmo volume do fluido lubrificante é utilizado de uma maneira mais eficiente, na produção da capacidade de carga auxiliar, por este tipo de cavidade, acarretando assim em uma capacidade de carga maior.

Enfim, analisando o campo de pressão (fig. 4.6) de dois casos específcos: semi-parabólica e esférica, pode-se compreender a maior eficiência do primeiro caso, visto que o campo de pressão do fluido sobre a região de uma cavidade semi-parabólica é totalmente positivo. Isto indica que o campo de pressão no fluido não é afetado pela abertura da cavidade, ou seja, esta cavidade atua como um mini canal convergente.

\section{A Profundidade}

O parâmetro $\Psi$ determina a profundidade da cavidade (Tabela 4.1), variandose este valor têm-se uma variação da profundidade, afinal ele representa a amplitude da funçāo $F(X, Y)$, definindo assim esta característica.

Os valores médios da capacidade de carga obtidos por meio de simulações computacionais, variando-se o valor do parâmetro $\Psi$, estão apresentados na figura 4.7. Para obtenção destes valores fol utilizado uma cavidade cilindrica com rampa, cuja forma é definida por: $F(X, Y)=\frac{1}{2} \cdot(1-X)$. Ainda, define-se

\footnotetext{
${ }^{5} \mathrm{O}$ principio da cavidade equavale a região de baixa densidade, apresentada na figura 4.5
} 
Parabólica

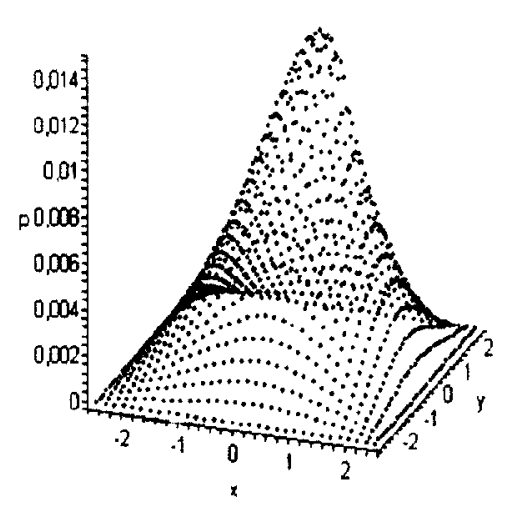

(a)
Estérica

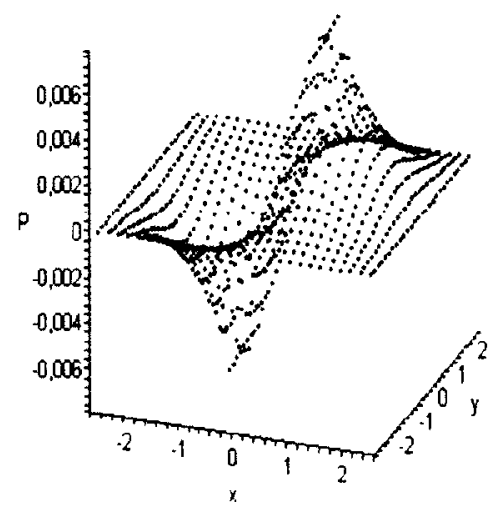

(b)

Figura 4.6: Comparaçao entre campo de pressão de cavidades semi parabólica (a) e esférica (b).

que $\gamma=1$ e $\xi=2,8$.

Analisando a figura 4.7, nota-se que a capacidade de carga máxima ocorre para $\Psi \simeq$ assumindo valores de 0,8 até 1,5 , ou seja, a profundiade ideal está em torno de uma ou duas vezes o valor do raio $R_{0}$ da cavidade, devido a

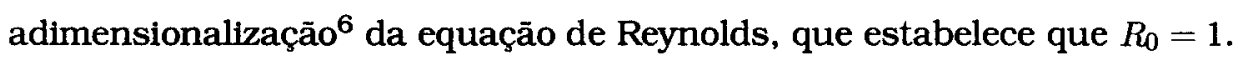

\section{O Diâmetro}

Antes de determinar esta caracteristica, convém ressaltar que o diâmetro da cavidade foi fixado pela adimensionalizaçāo da equação de Reynolds, logo, observando a equação (4.5), nota-se que o raio $R_{0}=1$, ou seja, o diâmetro da cavidade é uma constante no algoritmo. Entretanto, pode-se utilizar o parâmetro $\gamma=\frac{h_{0}}{R_{0}}$ para determinar o diâmetro da cavidade, pois a folga radial minima $h_{0}$ (espessura do filme) normalmente é pré-definida (conhecida) no

\footnotetext{
${ }^{6}$ Os valores apresentados na figura 4.14 são adimensionais, tendo como padrão $R_{0}=1$.
} 


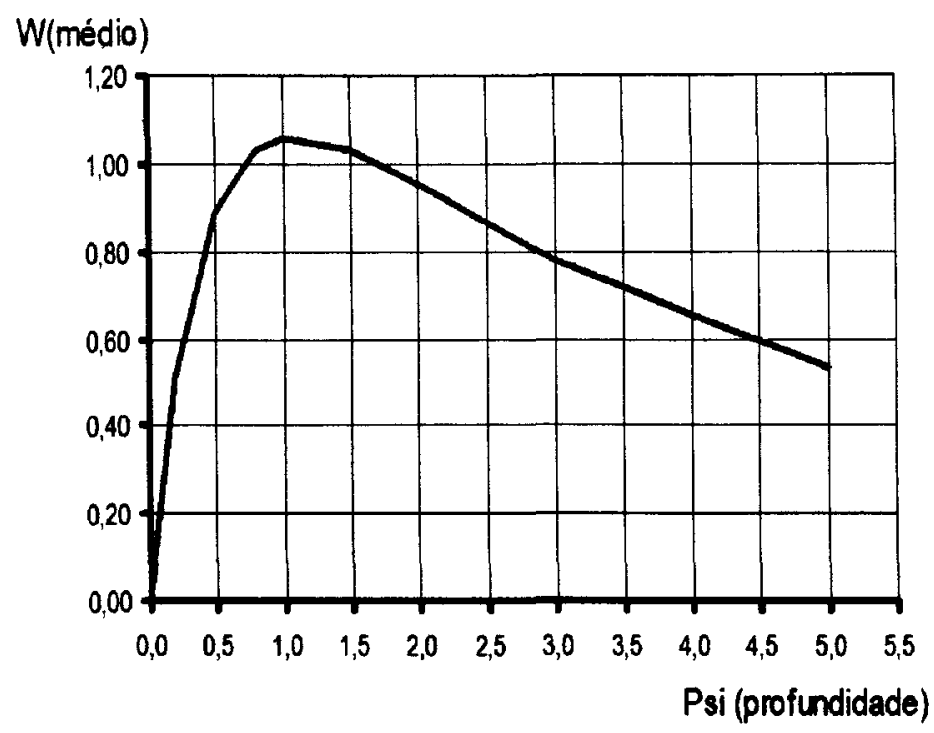

Figura 4.7: Variação do fator $\Psi$ que representa a profundidade da cavidade.

projeto de um mancal (Cap. 3).

Plotando os valores da capacidade de carga simulados versus este parâmetro, obtém-se um valor máximo para a capacidade de carga, definindo assim o valor ideal para $\gamma$ e conseqüentemente definindo um valor para $R_{0}$, visto que se conhece o valor de $h_{0}$. Para realização das simulações, utilizou-se uma cavidade cuja forma é a cilíndrica com rampa, sendo que $\Psi=1$ e $\xi=2$.

Analisando a figura 4.8 observa-se que um valor máximo para este parâmetro ocorre na região de 0,5 até 1,5 , indicando a melhor condição de lubrificaçāo. Logo, pode-se afirmar que, caso $h_{0} \simeq 10 \mu \mathrm{m}$ o valor do raio será $R_{0} \simeq 5-15 \mu \mathrm{m}$. O diâmetro logicamente é o dobro deste raio. Em vista disto, defindo o valor de $h_{0}$ conseqüentemente define-se as dimensões da cavidade.

A partir destes resultados, em conjunto com o (menor) valor definido para a rugosidade na tabela 3.1 (mancal radial), pode-se propor que;

$$
h_{o}>6 \mu m
$$

instituido pelo regime de lubrificação hidrodinâmico. Este condição acarreta 


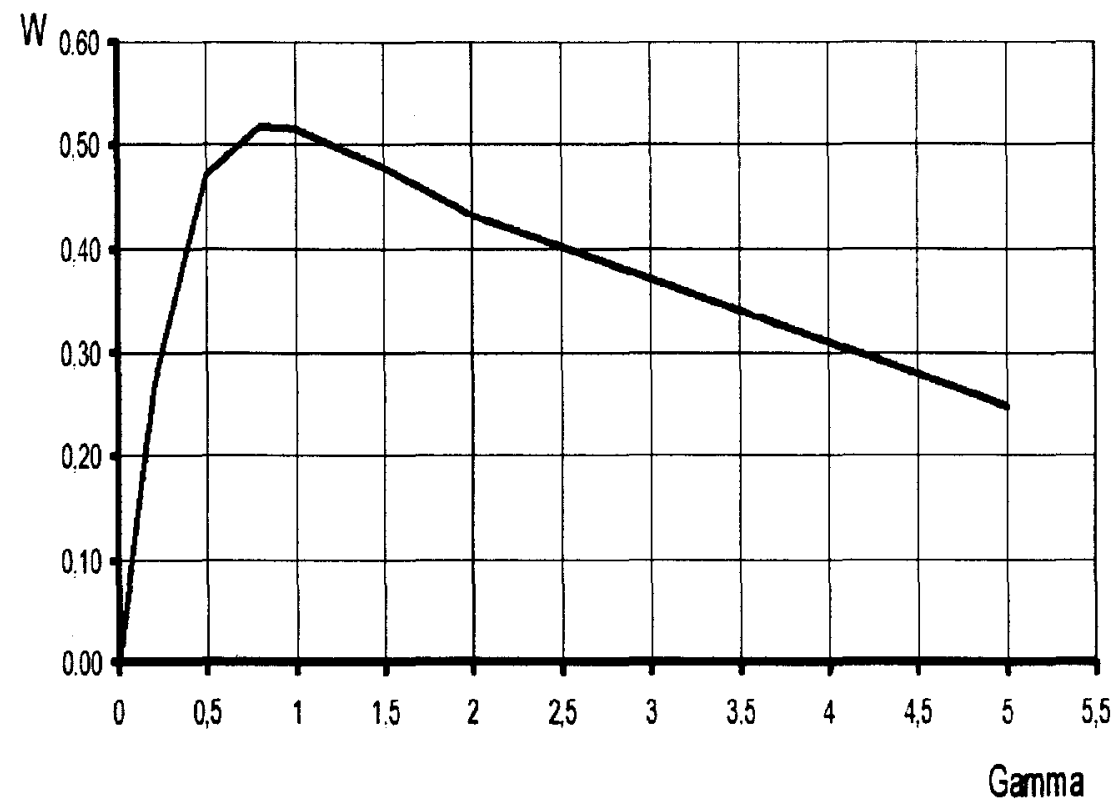

Figura 4.8: Determinação do Diâmetro Ideal

na seguinte definição;

$$
R_{0}>3 \mu m
$$

ressaltando que este valor é especifico para rugosidade sugerida na tabela 3.1, caso este valor seja alterado, novos valores para $R_{0} \mathrm{e} h_{o}$ serão definidos conseqũentemente.

\subsubsection{A densidade superficial das cavidades em uma placa}

A determinação da densidade superficial das cavidades será determinada considerando um placa texturizada, porque a capacidade de carga de uma única célula não é suficiente pra avaliar este parâmetro, como seră demonstrado a seguir.

\section{A determinação da capacidade de carga para um placa.}

Considerando um placa texturizada, cujo o campo de pressão de cada célula imaginária possa ser considerado independente, pode-se determinar a 
capacidade de carga desta placa, multiplicando o número de células imaginárias $N$ pela capacidade de carga de uma única célula, sendo que $N$ é definido por;

$$
N=\frac{L^{2}}{4 \cdot R_{1}^{2}}
$$

de acordo coma figura 4.9.

A partir da solução numérica $\left(P_{i, j}\right)$ da equação de Reynolds, determina-se a capacidade de carga $\left(W_{a}\right)$ definida pelo somatório (2.15);

$$
W_{a}=\sum_{i=0}^{N} \sum_{j=0}^{N} P_{i, j} . \Delta x . \Delta y
$$

representando uma única célula (seção 4.1).
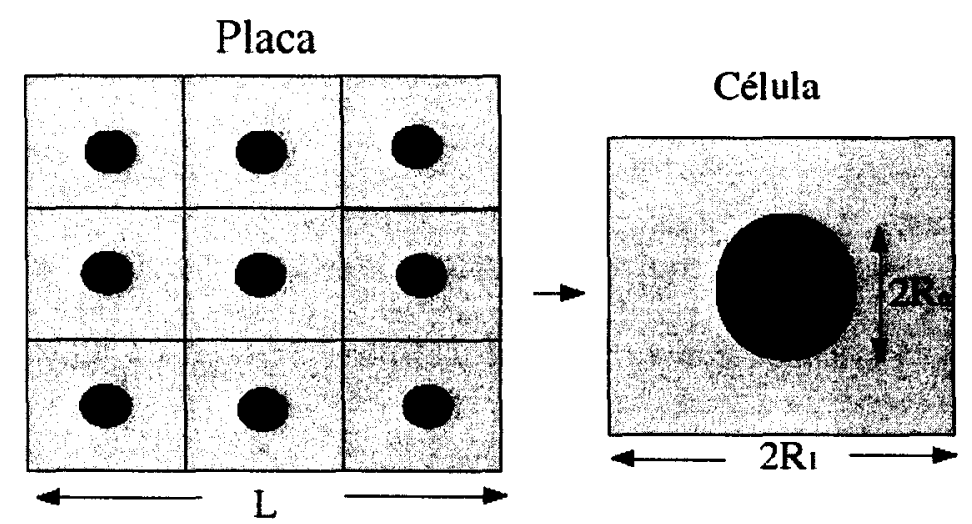

Figura 4.9: Placa texturizada com comprimento L e, ao lado, uma célula imaginária.

A capacidade de carga da placa devido a textura $W_{T}$ (Cap. 3) é definida pela soma da capacidade de carga de todas as células imaginárias, $W_{a}$, ou seja;

$$
W_{T}=\sum_{a=1}^{N} W_{a}
$$

logo, a condição de independência das células imaginárias implica que:

$$
W_{T}=\left(\frac{L^{2}}{4 \cdot R_{1}^{2}}\right) \cdot W_{a}
$$


utilizando a expressão para o número de células.

O fator dentro do parêntese na equação (4.11) pode ser convertido em outras constantes, como a densidade superficial (S), utilizando a equação (4.8);

$$
4 . R_{1}^{2}=\frac{\pi \cdot R_{0}^{2}}{S}
$$

acarretando desta forma na seguinte definição para a capacidade de carga:

$$
W_{T}=\left(\frac{L^{2}}{\pi \cdot R_{0}^{2}}\right) \cdot S \cdot W_{a}
$$

Portanto, em geral, um valor máximo para o somatório (2.15) multiplicado pela densidade superficial $S$, indica a melhor condição de lubrificação, em função deste parâmetro $(\xi)$, definindo assim a densidade superficial mais eficiente.

\section{Determinado a densidade superficial mais eficiente.}

Na equação (4.8) apresenta-se o parâmetro $\xi$, relacionado a densidade superficial das micro-cavidades;

$$
\xi=\frac{1}{2} \sqrt{\frac{\pi}{S}}
$$

contudo, ele representa a separação entre duas cavidades, logo reduzindo seu valor aumenta-se a densidade superficial, pois isto implica no aumento do número de cavidades na superficie de uma placa, conforme a figura 4.10 ilustra.

Portanto, pode-se definir que uma variação em $\xi$ pode ser iterpretada como uma variação em $R_{1}$, ou seja, uma variação na distância entre as cavidades.

Analisando a figura 4.11 , nota-se que a capacidade de carpa atinge um valor máximo próximo a $8 \% \mathrm{e}$, ainda, pode-se notar também que a medida que $S$ aumenta a curva decresce lentamente, indicando que densidades maiores que $8 \%$ podem ser utilizadas, entretanto, estes valores não apresentam variação significativa na capacidade de carga. Devemos ficar atentos ao limite de 
Densidade alta

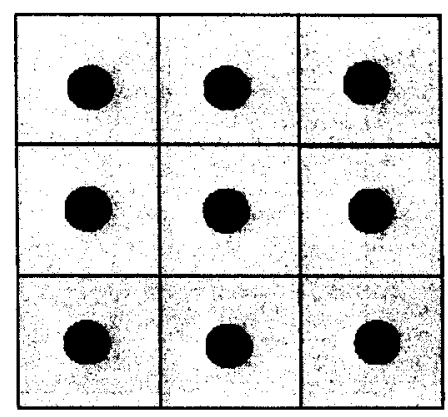

Densidade baixa

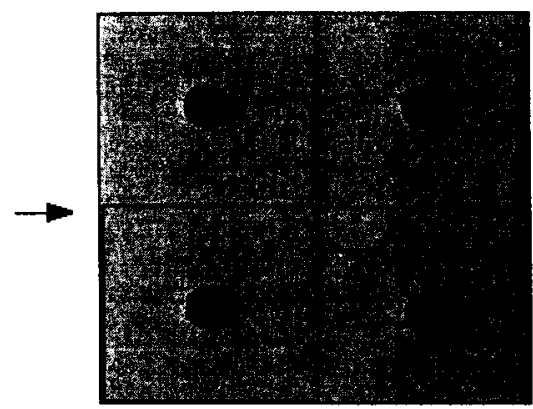

Figura 4.10: Alterando $\xi$ varia-se a densidade superficial de cavidades $S$ devido ao aumento do número de cavidades $(N)$.

fratura do material, desta forma sugere-se que seja utilizado densidades mais baixas.

Os valores apresentados nesta figura foram obtidos utilizando-se uma cavidade cuja forma é a cilindrica com rampa. A partir destes resultados define-se que a densidade superficial mais eficiente esta em torno de 8-10\%, implicando que $\xi \simeq 3$, em vista disto, têm-se a seguinte relação para $R_{1}$ :

$$
R_{1}=3 * R_{0}
$$

Deve-se salientar que, a densidade superficial foi avaliada pra outras formas de microcavidade, logo, o valor para a densidade (mais eficiente) utilizando uma cavidade cônica é maior que para uma cavidade cilíndrica com rampa, corroborando assim com a discussão anterior, visto que, a cavidade cilíndrica é mais eficiente que a cônica. Em vista disto, necessita-se de um número menor destas cavidades mais eficientes para produzir o mesmo efeito que aquelas menos eficientes.

A cavidade cônica apresenta, de acordo com a literatura [13], um valor eficiente para densidade próximo a $15-20 \%$ da área total, contra 8-10\% da cilindrica com rampa. 


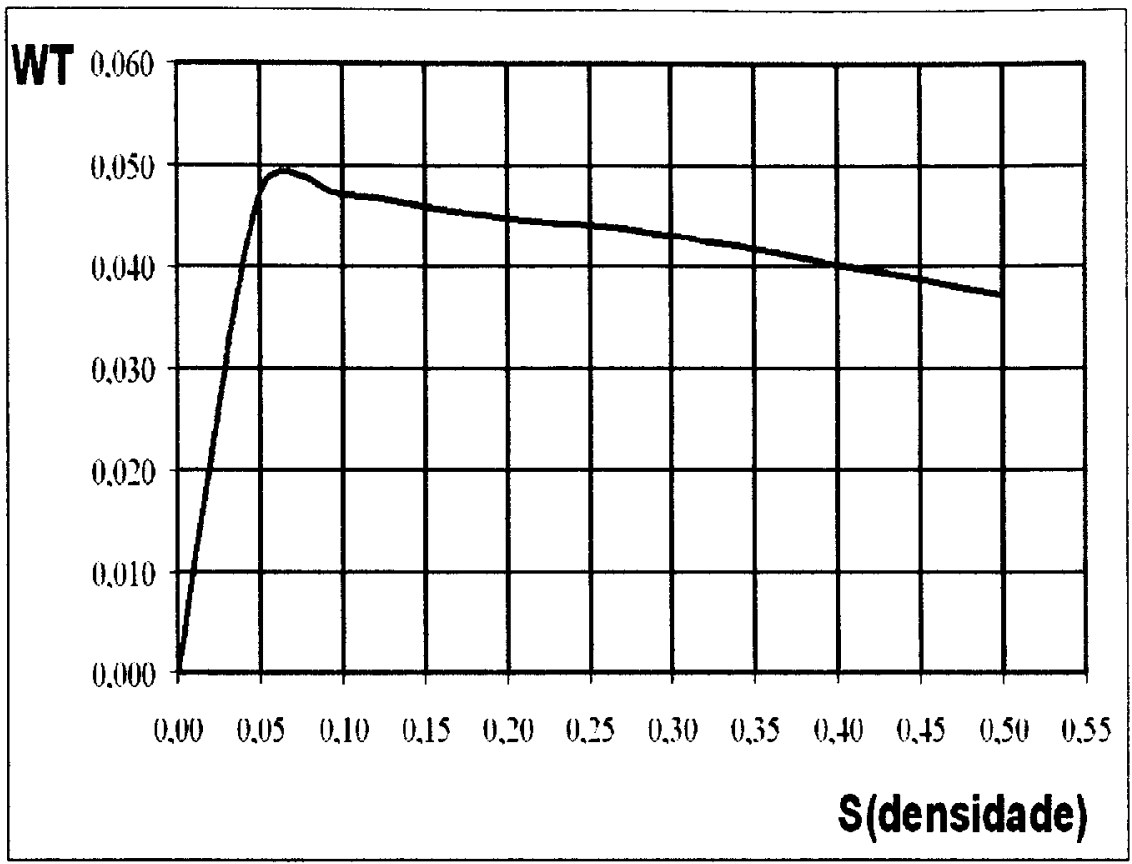

Figura 4.11: Relação da capacidade de carga com a densidade superficial. Utilizando uma cavidade cilindrica com rampa ( $\Psi=1,5$ e $\gamma=1,5)$ e fazendo $L=R_{0} \sqrt{\pi}$

\section{Resumindo:}

Utilizando os resultados obtidos anteriormente, pode-se contruir uma tabela para ilustrar a variação linear dos parâmetros, mostrando que, basta determinar espessura minima do filme lubrificante $h_{o}$, para que os outros parâmetros sejam definidos.

A espessura minima é determinada pelo número de Sommerfeld, apresentado no terceiro capítulo, que depende de parâmetros definidos pelo projetista do mancal. Na tabela a seguir apresenta-se alguns valores supostos para estes parâmetros, supondo as relações entre os parâmetros: 


$$
\begin{aligned}
& h_{o}=5 * \mathrm{Ra} \\
& h_{o}=0,8 * R_{0} \\
& h_{o}=2,4 * R_{1} \\
& h_{o}=0,8 * \Psi
\end{aligned}
$$

Todas estas relações são justificadas pelos resultados apresentados, exceto a primeira, que foi sugerida de modo a estabelecer o regime hidrodinâmico.

Tabela 4.3: Os parâmetros de texturas para um dado $h_{o}$ ou uma dada rugosidade Ra.

\begin{tabular}{|c|c|c|c|c|}
\hline $\operatorname{Ra}(\mu m)$ & $h_{0}(\mu m)$ & $R_{o}(\mu m)$ & $R_{1}(\mu m)$ & $\Psi(\mu m)$ \\
\hline \hline 0,01 & 0,05 & 0,04 & 0,12 & 0,04 \\
\hline 0,1 & 0,5 & 0,4 & 1,2 & 0,4 \\
\hline 1 & 5 & 4 & 12 & 4 \\
\hline 10 & 50 & 40 & 120 & 40 \\
\hline
\end{tabular}

Por fim, vale ressaltar que, o valor de $h_{o}$ é definido pelos parâmetros operacionais relacionados ao número de Sommerfeld, portanto, pode-se alterá-los determinando uma espessura que institua o regime hidrodinâmico e expresse o efeito da texturização na lubrificação. 


\section{Capítulo 5}

\section{Conclusões}

Este trabalho, sobre tribologia, é pioneiro no grupo de crescimento de cristais e materiais cerâmicos. O trabalho realizou essencialmente simulações numéricas do fluido em um mancal radial com a superficie texturizada, sob regime de lubrificação hidrodinâmica. Estas simulações foram realizadas a partir da equação de Reynolds.

Analisando os resultados destas simulações, pode-se afirmar que as microcavidades atuam como micro-mancais sobre o fluido, auxiliando desta maneira a lubrificação do mancal. Logo, isto justifica a utilização da texturização para a otimização da eficiência da lubrificação.

A partir da solução da equaçāo de Reynolds, definiu-se as características das microcavidades que maximizão a capacidade de carga, ou a espessura minima do fluido, com o intuito de determinar um padrão de texturização superficial ótimo.

Conforme os resultados apresentados pode-se afirmar que as formas geométricas mais eficientes para as microcavidades são aquelas que ocorre uma variação (queda) abrupta no início da cavidade. Então, utilizando a forma cilindrica com rampa, definimos os outros parāmetros das cavidades.

Analisando a maximização da capacidade de carga adimensional, para o modelo de uma célula unitária, podemos concluir que seu valor ótimo seria 
aproximadamente ao do raio de abertura da cavidade.

O raio de abertura $R_{0}$, por sua vez, é definido segundo sua relação com a espessura minima $h_{0}$ do filme lubrificante, pré-determinada pelo numéro de Sommerfeld. A relação é definida pela constante $\gamma$, definida anteriormente. Sabe-se que a maximização desta constante indica que o valor do raio deve ser aproximadamente $80 \%$ do valor da espessura mínima.

Enfim, a densidade superficial é definida pelo parâmetro $\xi$, que relaciona a distância entre duas cavidades $R_{1}$ com o raio de abertura destas. O valor ótimo para $\xi$ está por volta de 2,8 até 3,2 , indicando uma densidade superficial de $8 \%$ até $10 \%$ para a textura.

Em vista dos argumentos apresentados, pode-se concluir que uma vez definida a espessura minima do mancal, determina-se as caracteristicas da cavidade, produzida na texturizaçāo superficial a laser, que propicia a melhor condição de lubrificação para este elemento de máquina. Sendo assim definido o padrão ideal de texturização. 


\section{Capítulo 6}

\section{Anexos}

\subsection{Cavitação}

A cavitação é um agente de assimetrias no campo de pressão, pois, devido a este fenômeno, um limite inferior aos valores das pressões é introduzido, como será apresentado posteriormente.

Observando um diagrama de fases $(P x T)$ de uma substância (qualquer), nota-se que, para uma temperatura fixa, abaixo de uma certa pressão $P_{0}$, a substância se encontrará na fase gasosa. Esta pressão é denominada como a pressão de vapor desta substância.

Um fluido qualquer, que se encontra na fase líquida, durante o escoamento pode sofrer variações externas que provocarão uma reduçāo de pressão em certos pontos. Se a pressão atingir o valor da pressão de vapor surgirão bolhas de vapor dentro deste fluido. Este fenômeno de formação de bolhas em um líquido devido a redução da pressão é denominado como cavitação.

Para ilustrar melhor este fenômeno, pode-se apresentar algumas situações em que ocorrerá a cavitação. A partir da equação de Bernouli;

$$
P+\frac{\rho v^{2}}{2}=c t e
$$

pode-se afirmar que um aumento na velocidade implica numa redução da 
pressão, daí então, conforme se reduz a pressão inicia-se o fenômeno da cavitação. Em outras palavras, o aumento da velocidade pode causar cavitação em um fluido (e turbulência).

A partir da equação;

$$
\Delta P=\beta \frac{\Delta \rho}{\rho}
$$

que apresenta a relação da variação da pressão com a densidade, pode ser apresentada uma outra situação que ocorrerá cavitação. Analisando esta equação, pode-se afirmar que a redução da densidade, em algum ponto do fluido, acarretará numa redução da pressão, neste ponto. Portanto, uma redução de densidade provocará cavitação em um fluido, devido a redução da pressão $[40,41]$.

\subsection{Elementos de computação}

Apresenta-se o algoritmo desenvolvido neste trabalho, utilizando alguns comandos do software Maple, para resolução de EDPs, então, a seguir definese os comandos fundamentais deste software.

\subsubsection{Os comandos do software Maple ${ }^{1}$}

Atualmente existe diversos softwares (Maple, Matlab, Mathematica, etc) especializados em cálculos numéricos. O software Maple é freqüentemente utilizado para resolver equaçōes diferenciais, ele utiliza comandos de alto nivel que otimizam o algoritmo, evitando erros computacionais e, conseqüentemente, aumentando a precisão da solução.

O comando utilizado pelo maple para resolver EDPs: pdsolve, é muito versátil e pode ser utilizado em diversos problemas, porém, ele apresenta algumas limitações:

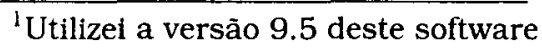


1. Não é capaz de resolver uma EDP de maneira analítica obedecendo as condições de contorno.

2. Não é capaz de resolver uma EDP eliptica de maneira numérica.

Para contornar estas limitações foi desenvolvido um algoritmo utilizandose o MDF. Este algoritmo inicia-se com a declaração da expressão analítica que representa a EDP, em seguida, apresenta-se a declaraçāo das expressōes numéricas dos termos contidos na EDP, como as aproximações para as derivadas parcials definidas anteriormente $[14,15,16]$.

> edp:=(Expressão analitica que representa a EDP);

$>\mathrm{X}:=($ Expressão numérica que representa algum elemento da EDP);

A seguir, estas expressões são associadas pelo comando eval, produzindo um sistema de equações. A sintaxe deste comando (eval) pode ser apresentada da seguinte forma:

$$
\begin{aligned}
& >\text { eq[i.j]:= "eval(edp, }\{\text { termo analítico = termo numérico respec- } \\
& \text { tivo\})" : }
\end{aligned}
$$

O comando eval, apresentado acima, converte os termos analíticos contidos na expressão da EDP em seus respectivos representantes numéricos, transformando uma EDP num sistema de equações.

O Maple possui o comando fsolve para resolver sistemas de equaçōes, este comando baseia-se essencialmente no método de eliminação de Gauss, sendo ainda incrementado por outros métodos para evitar as flutuações geradas pelos erros computacionais, como é apresentado no 'help' do software' ${ }^{2}$ A sintaxe deste comando pode ser apresentada da seguinte forma:

\footnotetext{
${ }^{2}$ Maple - Help - Introduction - Contents - Mathematics - Factorization and Solving Equations - Solve - Linear
} 
$>$ sol: = "fsolve $\left([\mathrm{eq}[i, \mathrm{j}]\},\left\{r_{i}\right]\right) "$

Neste comando eq[i,j] representa o sistema de equações a ser resolvido, $\left\{x_{i}\right\}$ são as variáveis incógnitas. A lista destes valores $\left(x_{i}=\right.$ número $)$ representa a solução numérica da EDP. A partir destes valores deve-se escolher a maneira mais adequada de apresentá-los, caso se utilize a forma gráfica devemos usar o comando plot3d para gerar a superfície que representa a soluçāo da EDP, na figura 6.1 foi contrastado a solução exata da EDP de Laplace com sua respectiva solução numérica[5, 15]
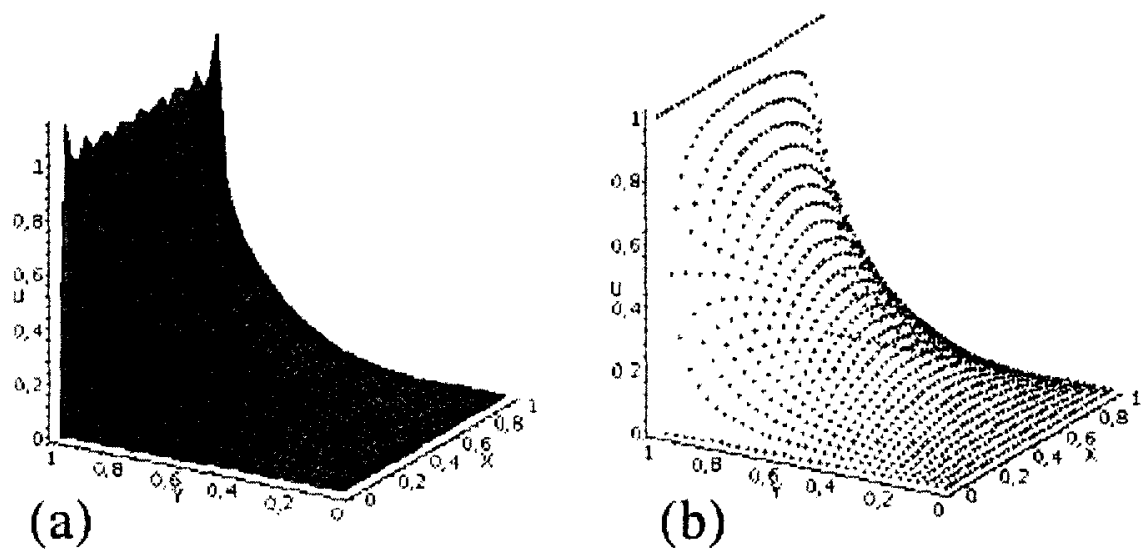

Figura 6.1: Comparação da solução analítica (a) e numérica (b) da solução da equação de Laplace.

\subsubsection{O algoritmo utilizado}

$$
\begin{aligned}
& \text { > restart; } \\
& \text { > Digits: }=15: \\
& \text { > gamma: }=1.5: \\
& \text { > psi }:=0.8:
\end{aligned}
$$


$>\mathrm{xi}:=2.8$ :

$>F(x, y):=\operatorname{sqrt}\left(1-x^{\wedge} 2-y^{\wedge} 2\right):$

$>\mathrm{H}(\mathrm{x}, \mathrm{y}):=$ piecewise $\left(\left(\mathrm{x}^{\wedge} 2+\mathrm{y}^{\wedge} 2\right)>1\right.$, gamma, $\left(\mathrm{x}^{\wedge} 2+\mathrm{y}^{\wedge} 2\right)=<1$, gamma $\left.+\mathrm{F}(\mathrm{x}, \mathrm{y})\right)$ :

$>\mathrm{N}:=60$ :

$>\mathrm{k}:=\left(2^{*} \mathrm{xi}\right) / \mathrm{N}$ :

$>$ bcl:=P(-xi,y)=0, P(xi,y)=0:

$>$ bc $2:=P(x,-x i)=0, P(x, x i)=0$ :

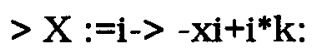

'X'[i]=X(i):

$>\mathrm{Y}:=\mathrm{j}->-\mathrm{xi}+\mathrm{j} * \mathrm{k}:$

$\mathrm{Y} \cdot[\mathrm{j}]=\mathrm{Y}(\mathrm{j})$ :

$>\mathrm{Px}:=\mathrm{i}->(\mathrm{P}[\mathrm{i}+1, \mathrm{j}]-\mathrm{P}[\mathrm{i}-1, \mathrm{j}]) /\left(2^{*} \mathrm{k}\right)$ :

$>P y:=j->(P[i, j+1]-P[i, j-1]) /(2 * k)$ :

$>P x x:=i->(P[i+1, j]-2 * P[i, j]+P[i-1, j]) / k^{\wedge} 2:$

$>$ Pyy $:=j->(P[i, j+1]-2 * P[i, j]+P[i, j-1]) / k^{\wedge} 2:$

$>\operatorname{ed} 1:=\operatorname{diff}\left(H(x, y)^{\wedge} 3^{*} \operatorname{diff}(\mathrm{P}(x, y), x), x\right)+\operatorname{diff}\left(H(x, y)^{\wedge} 3^{*} \operatorname{diff}(\mathrm{P}(\mathrm{x}, \mathrm{y}), y), y\right)=\operatorname{diff}(H(x, y), x):$

$>$ for $\mathrm{i}$ from $\mathrm{O}$ to $\mathrm{N}$ do

for $\mathrm{j}$ from $\mathrm{O}$ to $\mathrm{N}$ do

$e q[i, j]:=\operatorname{eval}(e d 1,\{x=X(i), y=Y(j), \operatorname{diff}(P(x, y), x)=P x(i), \operatorname{diff}(P(x, y), y)=P y(j)$, $\operatorname{diff}(P(x, y), x \$ 2)=P x x(i), \operatorname{diff}(P(x, y), y \$ 2)=P y y(j)\})$ od od;

$>$ for $\mathrm{i}$ from $\mathrm{O}$ to $\mathrm{N}$ do

$\mathrm{P}[\mathrm{i}, 0]:=\operatorname{rhs}(\mathrm{bc} 2[1]):$

$\mathrm{P}[\mathrm{i}, \mathrm{N}]:=\mathrm{rhs}(\mathrm{bc} 2[2])$ od:

$>$ for $\mathrm{j}$ from 1 to $\mathrm{N}-1$ do

$\mathrm{P}[0, \mathrm{j}]:=\operatorname{rhs}(\mathrm{bc} 1[1]):$

$\mathrm{P}[\mathrm{N}, \mathrm{j}]:=\mathrm{rhs}(\mathrm{bc} 1[2])$ od:

$>f s:=f$ solve $(\{$ seq $($ seq $($ eq $[1, j], i=1 . . N-1), j=1 . . N-1)\},\{$ seq $($ seq $(P[i, j], 1=1 . . N-1), j=1 . . N-$ 1)\}): 
$>\mathrm{ft}:=\operatorname{eval}(\operatorname{seq}(\operatorname{seq}([X(\mathrm{i}), \mathrm{Y}(\mathrm{j}), \mathrm{P}[\mathrm{i}, \mathrm{j}]], \mathrm{i}=0 . . \mathrm{N}), \mathrm{j}=0 . . \mathrm{N}), \mathrm{fs}):$

$>\mathrm{M}:=\operatorname{Matrix}([\mathrm{ft}])$ :

$>$ Lc: $=0$

$>\mathrm{A}:=\mathrm{k}^{\wedge} 2$ :

$>$ for $\mathrm{n}$ from 1 to $\left((\mathrm{N}+1)^{\wedge} 2\right)$ do

$>$ if $M[n, 3]>0$ then $L c:=L c+M[n, 3]$ fi od:

$>$ LC: $=\operatorname{LC}^{*} \mathrm{~A}$; 


\section{Referências Bibliográficas}

[1] A. Cameron; Basic Lubrication Theory, Longman, 1971.

[2] D. Duarte Jr; Tribologia, lubrificação e mancais de deslizamento, Editora Ciência Moderna, 2005.

[3] P. B. Neal; Film lubrication of wave-profiled pad thrust bearings, Int. J. Mec. Sci., Vol. 8, pp 525-540, 1966.

[4] H. E. Rashed; Effect of surface waviness on the hydrodynamic lubrication of a plain cylindrical sliding element bearing, Wear, 223, pp 1-6, 1998.

[5] I. Etsion e L. Burstein; A model for mechanical seals with regular microsurface structure, Trib. Trans., 39, pp 677-683, 1996.

[6] T. W. Lai; Development of Non-Contacting Spiral Groove Liquid Face Seals, Lubrication Engineering, 50, pp 625-640 1994.

[7] L. Burstein e D. Ingman; Effect of pore ensemble statistics on load support of mechanical seals with pore-covered faces, Journal of Tribology, 121,pp 927-932, 1999.

[8] I. Etsion, Y. Kligerman e G. Halperin; Analytical and Experimental Investigation of Laser-Textured Mechanical Seal Faces, Trib. Trans., 42, pp 511-516, 1999. 
[9] A. Ronen, Y. Kligerman e I. Etsion; Friction-reducing surface-texturing in reciprocating automotive components, Trib. Trans., 44, pp 359-366, 2001.

[10] I. Etsion, Y. Kligerman; Analysis of the Hydrodynamic Effects in a Surface Textured Circumferential Gas Seal, Trib. Trans., 44, pp 472-478, 2001.

[11] X. Q. Yu, S. He e R. L. Cai; Frictional characteristics of mechanical seals with a laser-textured seal face, J. Mat. Proc. Tec., 129, pp 463-466, 2002.

[12] M. Wakuda, Y. Yamauchi, S. Kanzaki e Y. Yasuda; Effect of surface texturing on friction reduction between ceramic and steel materials under lubricated sliding contact, Wear, 254, pp 356-363, 2003.

[13] I. Etsion, Y. Kligerman e V. Brizmer; A laser surface textured parallel thrust bearing, Trib. Trans., 46, pp 397-403, 2003.

[14] I. Etsion, G. Halperin, Y. Kligerman e V. Brizmer; Experimental investigation of laser surface textured parallel thrust bearing, Trib. Let., 17, pp 295-300, 2004.

[15] I. Etsion; Improving tribological performance of mechanical components by laser surface texturing, Trib. Let., 17, pp 733-737, 2004.

[16] G. C. Buscaglia, R. F. Ausas e M. Jai; Optimization tools in the analysis of micro-textured lubricated devices, Design and Optimization Symposium, Rio de Janeiro, Brasil, 2004.

[17] M. Pascovici e V. Marian; An analytical and numerical approach of load carrying capacity for partially textured sliders, 12th conference on EHD Lubrication and Traction, Suceava, Romenia, October 8-9, 2004.

[18] A. Kovalchenko, O. Ajayi, A. Erdemir, G. Fenske e I. Etsion; The effect of laser surface texturing on transitions in lubrication regimes during unidirectional sliding contact, Trib. Int., Vol.38, pp 219-225, 2005. 
[19] G. Ryk, Y. Kligerman, I. Etsion, A. Shinkarenko; Experimental investigation of partial laser surface texturing for piston-ring friction reduction, Trib. Trans., Vol. 48, pp 583-588, 2005.

[20] S. M. Pimenov, V. I. Konov, T. V. Kononenko, et. al. ; Laser applications in tribology of hard materials and coatings, New diamond and frontier carbon technology, 10, pp 123-136, 2000.

[21] G. Dumitru, V. Romano, H. Weber, H. Haefke, Y. Gerbig e E. Pflüger; Laser microstructuring of steel surfa ces for tribological applications, Appl. Phys. A, 70, pp 485-487, 2000.

[22] A. Volchok, G. Halperin e I. Etsion; The effect of surface regular microtopography on fretting fatigue life, Wear, 253, pp 509-515, 2002.

[23] A. Edemir; Review of engineered tribological interfaces for improved boundary lubrication, Trib. Int. , 38, pp 249-256, 2005.

[24] S. P. Xavier; Caracterização e avaliação da biocompatibilidade do titânio submetido a diferentes tratamentos de superficie, Tese, Unesp, Araçatuba, SP, Brasil, 2002.

[25] U. Pettersson e S. Jacobson; Influence of surface texture on boundary lubricated sliding contacts, Trib. Int., Vol. 36, pp 857-864, 2003.

[26] K. Gururajan e J. Prakash; Roughness effects in a narrow porous journal bearing with arbritary porous wall thickness, Int. J. Mec. Science, 44, pp 1003-1016, 2002.

[27] H. H. Cheng, R. L. Jaw e L. C. Hsiu; Combined effects of couple stresses and surface roughness on lubrication of short journal bearings, Industrial Lubrication and Tribology, V55, pp 233-243, 2003. 
[28] H. L. Chiang, C. H. Hsu e J. R. Lin; Lubrication performance of finite journal bearings considering effects of couple stresses and surface roughness, Tribology International, 37, pp. 297-307, 2004.

[29] R. B. Siripuram e L. S. Stephens; Effect of deterministic asperity geometry on hydrodynamic lubrication, J. Trib. Trans.(ASME), Vol. 126, pp 527$534,2004$.

[30] C. Sinanoglu; The analysis of the effects of surface roughness of shafts on journal bearings using recurrent hybrid neural network, Ind. Lub. Trib., Vol.56, pp 324-333, 2005.

[31] W. Z. Wang, H. Chen, Y. Z. Hu e H. Wang; Effect of surface roughness parameters on mixed lubrication characteristics, Trib. Int., Vol.39, pp 522$527,2006$.

[32] V. I. Grabovskii and A. N. Kraiko; Optimum design of infinite journal bearing with a minimum of the friction moment, Journal of Applied Mathematics and Mechanics, Vol. 63, 3, pp 453-461, 1999.

[33] B. S. Yang, Y. H. Lee, B. K. Choi e H. J. Kim; Optimum design of short journal bearings by artificial life algorithm, Trib. Int., 34, pp 427-435, 2001.

[34] S. Boedo e S. L. Eshkabilov; Optimal shape design of steadily loaded journal bearings using genetic algorithms, Tribology Transactions, 46, pp 134-143, 2003.

[35] V. Kumar, J. Aggarwal e S. K. Ghai; Performance characteristcs of holeentry hybrid journal bearing of different configurations, (IE) Journal-MC, Vol. 85, pp 20-25, 2004. 
[36] C. Sinanoglu, F. Nair e M. B. Karamis; Effects of shaft surface texture on journal bearing pressure distribution, J. Mat. Proc. Tec., 168, pp 344-353, 2005.

[37] T. Suganami, K. Satoh, K. Matsukawa e K. Tsukamoto; The effect of the direction of shaft inclination and its magnitude oil journal sliding bearing performance, Journal of Jap. Soc. of Tribologists, Vol.50, pp 47-54, 2005.

[38] L. San Andres L e O. de Santiago; Identification of journal bearing force coefficients under high dynamic loading centered static operation; Trib. Trans., Vol.48, pp 9-17, 2005.

[39] A. Fatu, M. Hajjam e D. Bonneau; A new model of thermoelastohydrodynami lubrication in dynamically loaded journal bearings, J. Trib. Trans. (ASME), Vol. 128, pp 85-95, 2006.

[40] L. D. Landau e E. M. Lifshitz; Fluid Mechanics, Editora B.H., 1984.

[41] Hughes,W.F. e Brighton, J.A. ; Dinâmica dos fluidos, McGraw Hill, 1974.

[42] R. Bassani e B. Piccigallo; Hydrostatic lubrication, Elsevier, 1992.

[43] R. Iorio Jr; Equações diferenciais parciais: uma introdução, Rio de Janeiro, Projeto Euclides-IMPA, 1988.

[44] L. M. B. Napolitano; Implementação numérica do método Level Set para programação de curvas e superficies, Dissertação, IFSC, USP, Brasil, 2004 .

[45] A. Sommerfeld; Partial differential equations in physics, New York, Academic Press, 1949.

[46] A. O. Fortuna; Técnicas computacionais para dinâmica dos fluidos: conceitos básicos e aplicaçōes, São Paulo, EDUSP, 2000. 
[47] G. D. Smith; Numerical Solution of Partial Differential Equations: Finite Difference Methods, Oxford University Press, 1985.

[48] D. G. Zill e M. R. Cullen; Equaçōes diferenciais, V.4, Makron Books, 2003.

[49] C. F. Gerald e P. O. Wheatley; Applied Numerical Analysis, sixth edition, Addison-Wesley, 1999.

[50] http://mea.pucminas.br/palma/elemaqapostila.html

[51] B. M. Purquerio; Tribologia, Vol. II - Lubrificantes e Regimes de lubrificação, USP, São Carlos, 1998.

[52] Juliano A. Araujo; Influência da texturização por laser Nd:YAG no comportamento tribológico de um recobrimento de cromo eletro-depositado em aço carbono, Dissertação, Redemat, UFOP, 2002.

[53] John F. Ready; Lia handbook of laser materials processing, Magnolia Publishing, 2001.

[54] P.Das; Lasers and optical engineering, Springer-Verlag, New York, 1991.

[55] S. Nolte, C. Momma, H. Jacobs, A. Tünnermann, B.N. Chichkov, B. Wellegehausen e H. Welling; Ablation of metals by ultrashort laser pulses , J. Opt. Soc. Am. B, Vol 14, pp 2716-2722, 1997.

[56] D. von der Linde e K. Sokolowski-Tinten; Physical mechanisms of short pulse laser ablation, Universität Essen, Essen, Alemanha, 1997.

[57] W. W. Duley; $\mathrm{CO}_{2}$ lasers: effetcts and applications, Academic Press, 1976.

[58] Renato Portugal; Introdução ao Maple, Laboratório Nacional de Computação Científica, Petrópolis-RJ, 2002. 
[59] Bruce W Char, K. O. Geddes, G. H. Gonnet, B. L. Leong, M. B. Monagan e S. M. Watt: Maple V: language, reference e manual, Springer-Verlag, 1991. 